\title{
Modeling techniques of TCM/PCM-materials on micro-, meso- and macro scales
}

April 2011

Paul Gantenbein

Camilo Rindt

A report of the IEA Solar Heating and Cooling / Energy Conservation through Energy Storage programme - Task 42/Annex 24:

Compact Thermal Energy Storage: Material Development for System Integration
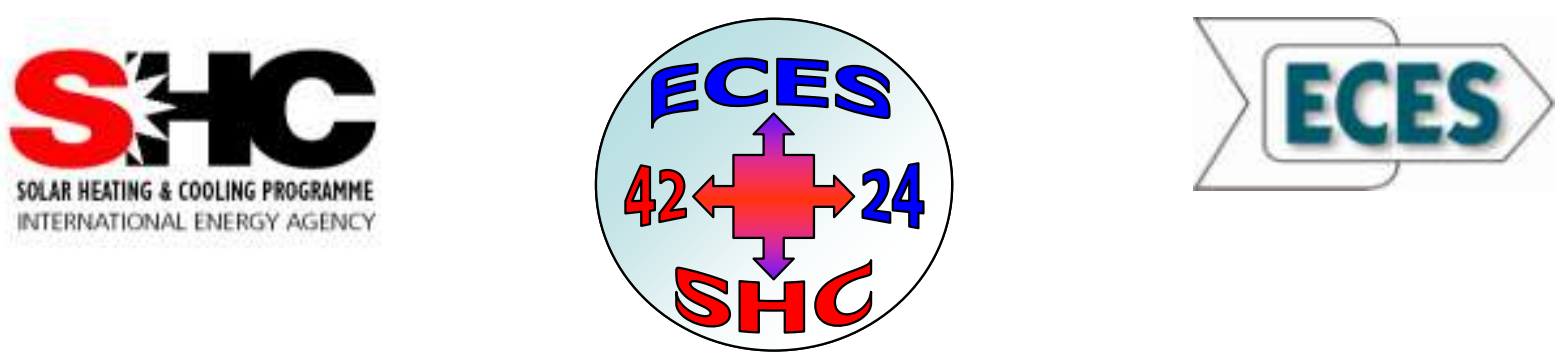


\section{Modeling techniques of TCM/PCM-materials on micro-, meso- and macro scales}

by

Paul Gantenbein, Camilo Rindt 


\section{Reports of the EIA SHC/ECES Task42/Annex24: Compact thermal energy storage materials development for system integration.}

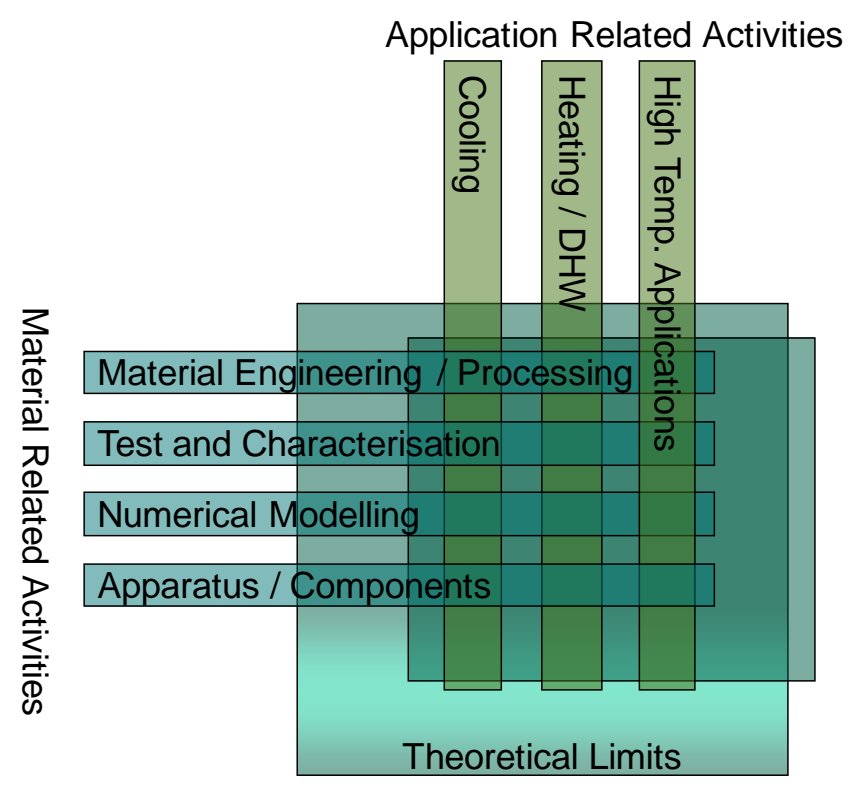

In the Task4224, a large group of thermal energy storage experts collaborated with the aim to further develop materials for compact thermal energy storage and systems for the integration of compact thermal energy storage in heating or cooling systems. The activities were performed from 2009 until the end of 2012 and were divided in working groups, according to the structure depicted here. The groups worked on a number of deliverables, that are condensed into reports.

On materials development side, the work was subdivided into materials engineering and processing, testing and characterisation of materials, numerical modelling and aspects connected to the design of the storage apparatus and other components. The application work was subdivided into three different temperature ranges: from cooling to heating/domestic hot water to high temperature. Furthermore, there was a separate working group on the theoretical limits of thermal energy storage.

One of the deliverables of the Task4224 is a database in which the material properties of PCM and TCM are collected. The database is still completed and only accessible for the Task Experts.

From the Task4224 website (http://task42.iea-shc.org), the following report is available:

Modeling techniques of TCM/PCM-materials on micro-, meso- and macro scales Describing the state of the art for numerical modeling of thermal energy storage materials of the class phase change materials (PCM) or thermochemical materials (TCM) on three different length scales.

In the Task, also a collection was made of experimental data sets that can be used for validation of numerical models. These data sets are available for Task Experts only.

Other reports that will follow soon:

Development of a Test-Standard for PCM and TCM Characterization

Summarizing the results obtained so far for the measurement of heat storage capacity and melting behavior of PCMs using DSC devices.

Thermal Storage apparatus design

A description of a possible design approach for thermal energy storage devices and a 
summary of the designs that a number of research groups adopted for their TES development.

Boundary conditions for thermal energy cooling storage applications

Describing the boundary conditions that should be met when designing TES cooling systems for applications in the temperature range from -20 to $+20^{\circ} \mathrm{C}$.

\section{Development of Space Heating and Domestic Hot Water Systems with Compact Thermal Energy Storage}

A description of the development of 8 different systems for the energy storage of heat for heating and domestic hot water.

\section{New or improved materials for thermal energy storage applications}

Giving an overview of a number of developments in thermal energy storage materials, from solid-solid phase change materials, sugar alcohol based PCMs, micro-encapsulated PCMs to novel sorption materials and metal-oganic framework materials.

Materials and systems for High temperature Thermal Energy Storage

Several topics are treated in this report : material selection and characterisation, pilot plant experimentation, life cycle assessment for concentrated solar power thermal storage and

Projects and activities on high temperature thermal energy storage

Gives a description of applications of thermal energy storage for high temperatures and on a number of materials and characterisation developments. 


\section{Modelling techniques of TCM/PCM-materials on micro-, meso- and macro scales}

\section{MOTIVATION}

Thermal energy can be stored in materials because of their internal energy based on the electronic structure of the basic particles like atoms, molecules, clusters or just the "unit cell". The knowledge of the thermodynamic properties and the dynamical behaviour of all the materials and the components is the basis for the design of a storage device. In the developing process of a heat storage device experiments play a dominant role because in the prototype stadium a physical system has to be built to acquire measurement data for a fine tuning of the pilot and market product. In this development process numerical modelling plays the role of reducing the number of time consuming and cost intensive experiments. And modelling should help to understand how the limiting parameters can or should be adapted for the assigned task.

The motivation is to make a transition from rules of thumb to more precise analytic functions for the design of storage units with a low number if input parameters to transfer the dynamical behaviour through equations to a system simulation tool like TRNSYS.

The authors do not have the intention to give a complete overview of all the numerical modelling techniques available on the micro-, meso- and macro-scale. Such a complete overview would need a detailed literature study which was not possible within the limited time available. Therefore, the report at hand presents an overview of the numerical modelling techniques as used by the active participants in the working group WGA3 on Numerical Modelling.

\section{OUTLINE}

The document is structured in two main parts focussing on PCM and TCM modelling. Both main parts are subdivided into subchapters on modelling techniques used on the micro-, meso- and macro-scales in the time- and length-scale framework as depicted in Figure 1, and in modelling techniques used in multi-scale approaches and in reactor simulations. Although quite important, no one of the participants of this working group was active in solving thermo-mechanical problems and was able to deliver input for the modelling techniques used to solve such problems. All author contributions start with a short introduction. This introduction is followed by a short description of the physical problem at hand and the solution procedure used. Then results are presented and conclusions are drawn up. 
Table of contents

REPORTS OF THE EIA SHC/ECES TASK42/ANNEX24: COMPACT THERMAL ENERGY STORAGE MATERIALS DEVELOPMENT FOR SYSTEM INTEGRATION.

MODELLING TECHNIQUES OF TCM/PCM-MATERIALS ON MICRO-,

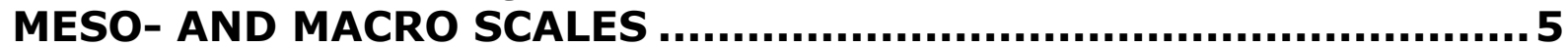

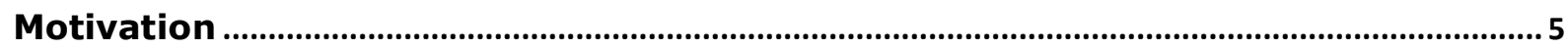

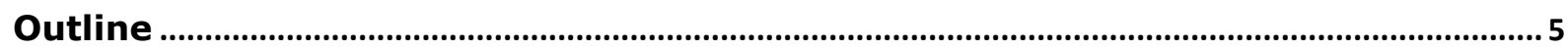

PHASE CHANGE MATERIAL MODELS.............................................. 8

Introduction

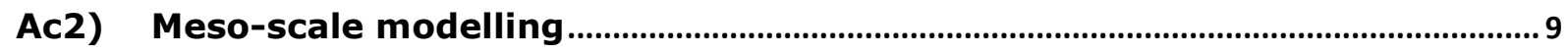

Numerical modelling of the phase change using Lattice Boltzmann Method....................... 9

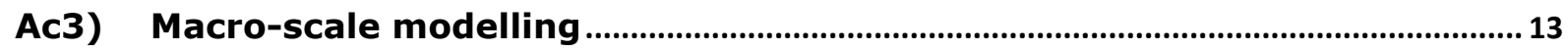

Heat transfers in wall including PCM: conduction and convection....................................... 13

Further investigation of enthalpy-porosity method in solid-liquid phase change............. 18

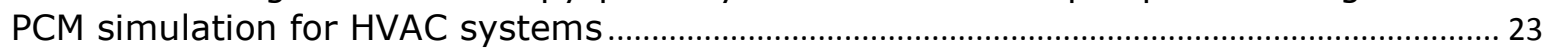

Characterization of melting and solidification in a real scale PCM-air heat exchanger:

Numerical model and experimental validation .......................................................................... 24

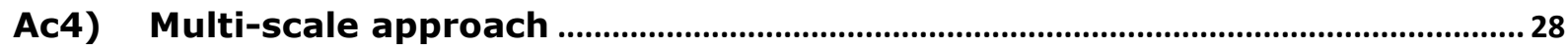

A TRNSYS Type for the Simulation of Building Wall Containing PCM .................................. 28

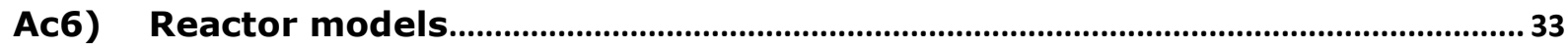

A Photovoltaic panel coupled with a phase changing material heat storage system in hot climates

THERMO-CHEMICAL MATERIAL MODELS ...................................... 36

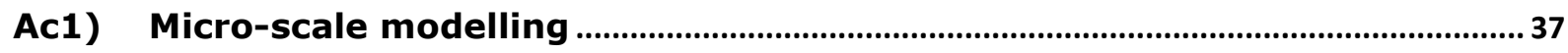

Atomistic simulations for heat transfer and chemical reactions on micro/nano-scale.... 37

Hybrid Molecular Dynamics - Monte Carlo simulations for the flow in a micro-channel 44

Ac3) Macro-scale modelling

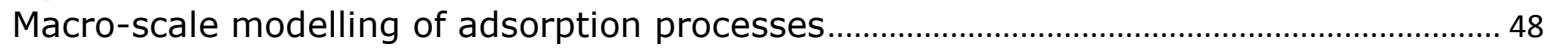

CLOSURE .............................................................................. 54

SHORT DESCRIPTION OF TASK 42/ ANNEX 24............................55

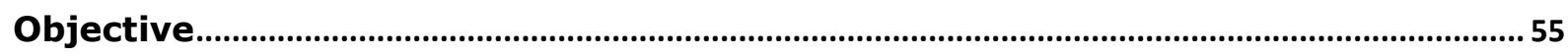

Scope 


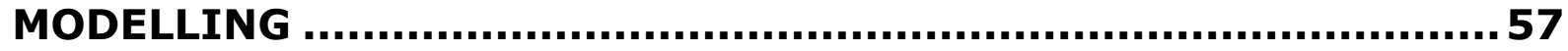

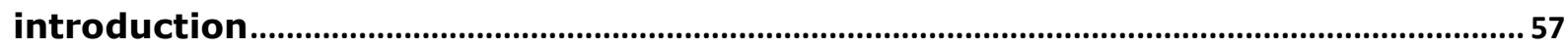

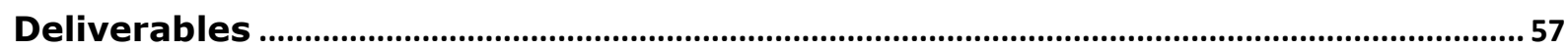

IEA SOLAR HEATING AND COOLING PROGRAMME .....................59 


\section{Phase Change Material Models}

\section{INTRODUCTION}

Nowadays, thermal energy storage systems are essential for reducing dependency on fossil fuels and then contributing to a more efficient environmentally benign energy use.

Thermal energy storage can be accomplished either by using sensible heat storage or latent heat storage. Sensible heat storage has been used for centuries by builders to store/release passively thermal energy, but a much larger volume of material is required to store the same amount of energy in comparison to latent heat storage. The principle of the phase change material (PCM) use is simple. As the temperature increases, the material changes phase from solid to liquid. The reaction being endothermic, the PCM absorbs heat. Similarly, when the temperature decreases, the material changes phase from liquid to solid. The reaction being exothermic, the PCM desorbs heat.

The phase change materials used in applications can be either organic materials or inorganic materials. The organic PCM are paraffins, fatty acids and the polyethylene glycol (PEG). They present a congruent phase change, they are not dangerous, and they have a good nucleation rate.

The advantages of organic PCM are:

- availability in a large temperature range,

- freeze without much super cooling,

- ability to melt congruently,

- self nucleating properties,

- compatibility with conventional material of construction,

- no segregation,

- chemically stable,

- high heat of fusion,

- safe and non-reactive,

- recyclable.

The disadvantages of organic PCM are:

- low thermal conductivity,

- low volumetric latent heat storage capacity,

- flammable (depending on containment).

The inorganic PCM are salt hydrates.

The advantages of inorganic PCM are:

- high volumetric latent heat storage capacity,

- low cost and easy availability,

- sharp phase change,

- high thermal conductivity,

- non-flammable.

The disadvantages of inorganic PCM are:

- high volume change,

- super cooling,

- segregation.

PCM are used in systems for passive or active applications. The objective of numerical modeling is to predict the behavior of systems depending on the heat and/or mass transfers involved. 


\section{AC2) MESO-SCALE MODELLING}

\section{Numerical modelling of the phase change using Lattice Boltzmann Method \\ Frédéric KUZNIK \& Joseph VIRGONE \& Kevyn JOHANNES, Thermal Sciences Center of Lyon, France.}

\section{INTRODUCTION}

A new way of using PCM in building walls is to fill glass bricks with an eutectic of fatty acids; such wall allowing to avoid overheating in summer and decrease energy consumption in winter. In this configuration, the phase change is driven by natural convection accuring during the melting and freezing processes. The interplay between the fluid flow and the moving boundary leads to a complex dynamical behavior, as the position of the solid liquid interface becomes one of the unknowns of the problem. The moving boundary problem usually requires sophisticated numerical schemes such as front tracking methods (Bertrand et al., 1999) and adaptative grid methods (Mencinger, 2004). However, benchmark studies show that the resolution of the problem is quite difficult and leads to differences in the results, especially for real cases.

The lattice Boltzmann method, developed over the last two decades (Sukop and Thorne, 2006), provides a powerful alternative approach for studying convection involving phase changes. LBM can easily be parallelized, complex geometries can be easily implemented and melting/freezing can be mesoscopically modelled (Kuznik et al., 2007).

The objective of our work is first, to develop a new numerical model of the phase change with convection using LBM and second, to validate it using a home-made experiment.

\section{PHYSICAL MODEL}

$f_{i}$ for $i=0, \ldots, 8$ being the density distribution function in the $i$-th direction (see Figure 1 ), the evolution equation is given by:

$$
f_{i}\left(\vec{x}+\overrightarrow{e_{i}} \Delta t, t+\Delta t\right)-f_{i}(\vec{x}, t)=\frac{\Delta t}{\tau}\left(f_{i}^{e q}(\vec{x}, t)-f_{i}(\vec{x}, t)\right)
$$

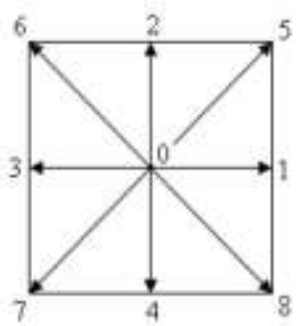

Figure 1: D2Q9.

And then the macroscopic quantities are:

$$
\begin{gathered}
\rho=\sum_{i=0}^{8} f_{i} \\
\rho \cdot \vec{u}=\sum_{i=0}^{8} f_{i} \cdot \vec{e}_{i} \\
v=c_{s}^{2} d t(\tau-0.5)
\end{gathered}
$$

The equilibrium distribution function is given by:

$$
f_{i}^{e q}=\rho \omega_{i}\left[1+3 \overrightarrow{e_{i}} \cdot \vec{u}+4.5\left(\overrightarrow{e_{i}} \cdot \vec{u}\right)^{2}-1.5 \vec{u}^{2}\right]
$$


with $\omega_{0}=16 / 36, \omega_{1,2,3,4}=4 / 36$ and $\omega_{5,6,7,8}=1 / 36$.

For the temperature, the distribution function is $g_{i}$, for $i=0, \ldots, 4$ (see Figure 2):

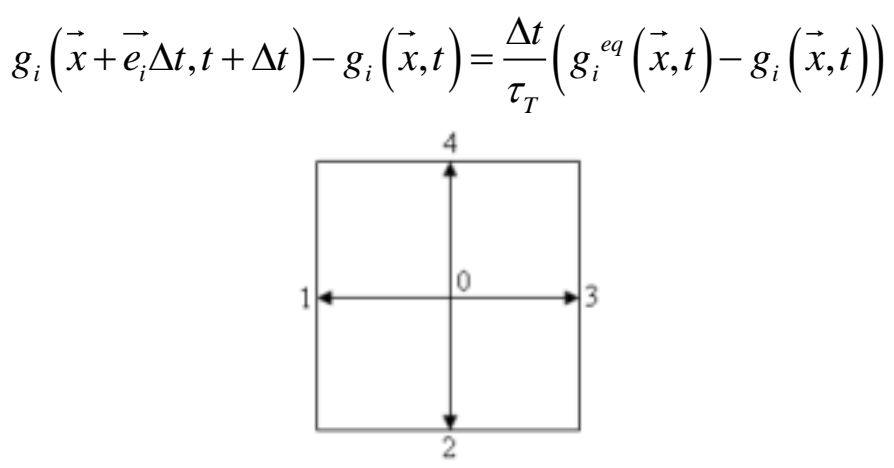

Figure 2: D2Q5.

And then the macroscopic quantities are:

$$
\begin{gathered}
T=\sum_{i=0}^{4} g_{i} \\
\kappa=c_{s}^{2} d t\left(\tau_{T}-0.5\right) \\
\operatorname{Pr}=\frac{2 \tau-1}{2 \tau_{T}-1}
\end{gathered}
$$

The equilibrium distribution function is given by:

$$
g_{i}^{e q}=T \omega_{T i}\left[1+3 \overrightarrow{e_{i}} \cdot \vec{u}\right]
$$

with $\omega_{T 0}=1 / 3, \omega_{T 1,2,3,4}=1 / 6$.

The liquid fraction is used to calculate the local enthalpy.

\section{COMPUTATIONAL PROCEDURE}

The equation system is totally explicit and then there is no specific treatment. The LBM calculation requires many simple calculations then we parallelize the procedure. For that purpose, Graphics Processing Units (GPU) are used (Kuznik et al., In Press). The gain, compares with CPU, is about 150 times faster.

\section{RESULTS \& DISCUSSION}

1) Natural convection in a cavity filled with air The first test concern the natural convection modelling using the simple test case of the 2D differentially heated cavity filled with air (Figure 3 ).

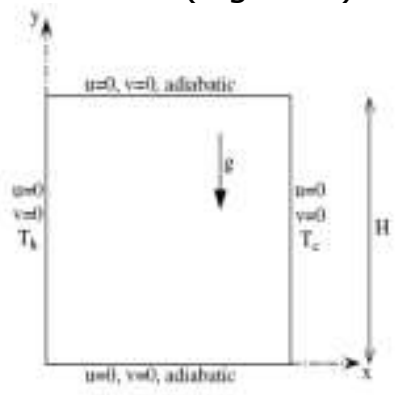

Figure 3: Natural convection in a 2D square cavity. 
The tables 1 and 2 show the comparisons with data from literature. The results are in good agreement for Rayleigh number up to $10^{8}$.

\begin{tabular}{|c|c|c|c|c|c|}
\hline & & $R a=10^{3}$ & $R a=10^{4}$ & $R a=10^{5}$ & $R a=10^{6}$ \\
\hline \multirow[t]{3}{*}{$u_{\max }$} & de Vahl Davis (1983) & 3.649 & 16.178 & 34.730 & 64.630 \\
\hline & Hortmann et al. (1990) & - & 16.180 & 34.740 & 64.837 \\
\hline & Present & 3.636 & 16.167 & 34.962 & 64.133 \\
\hline \multirow[t]{3}{*}{$y_{\max }$} & de Vahl Davis (1983) & 0.813 & 0.823 & 0.855 & 0.850 \\
\hline & Hortmann et al. (1990) & - & 0.825 & 0.837 & 0.850 \\
\hline & Present & 0.809 & 0.821 & 0.854 & 0.860 \\
\hline \multirow[t]{3}{*}{$v_{\max }$} & de Vahl Davis (1983) & 3.697 & 19.617 & 68.590 & 219.360 \\
\hline & Hortmann et al. (1990) & - & 19.629 & 68.639 & 220.461 \\
\hline & Present & 3.686 & 19.597 & 68.578 & 220.537 \\
\hline \multirow[t]{3}{*}{$x_{\max }$} & de Vahl Davis (1983) & 0.178 & 0.119 & 0.066 & 0.038 \\
\hline & Hortmann et al. (1990) & - & 0.120 & 0.883 & 0.039 \\
\hline & Present & 0.174 & 0.120 & 0.067 & 0.038 \\
\hline \multirow[t]{3}{*}{$N u_{0}$} & de Vahl Davis (1983) & 1.117 & 2.238 & 4.509 & 8.817 \\
\hline & Hortmann et al. (1990) & - & 2.244 & 4.521 & 8.825 \\
\hline & Present & 1.117 & 2.246 & 4.518 & 8.792 \\
\hline
\end{tabular}

Table 1: $\quad$ Comparison of laminar flow with previous work for the square heated cavity with imposed temperatures.

\begin{tabular}{|c|c|c|c|}
\hline & & $R a=10^{7}$ & $R a=10^{3}$ \\
\hline$u_{\text {nat }}$ & $\begin{array}{l}\text { Markatos ef al (1984) } \\
\text { Le Quere (1991) } \\
\text { Present }\end{array}$ & $\begin{array}{l}148.589 \\
148.768\end{array}$ & $\begin{array}{l}5143 \\
321.876 \\
321.457\end{array}$ \\
\hline $5_{\operatorname{man}}$ & $\begin{array}{l}\text { Markates et al (1984) } \\
\text { Le Quere (1991) } \\
\text { Present }\end{array}$ & $\begin{array}{l}0.879 \\
0.881\end{array}$ & $\begin{array}{l}0.941 \\
0.928 \\
0.940\end{array}$ \\
\hline$x_{\max }$ & $\begin{array}{l}\text { Markatos of at (1984) } \\
\text { Le Quere (1991) } \\
\text { Preseat }\end{array}$ & $\begin{array}{l}699236 \\
702.029\end{array}$ & $\begin{array}{l}1812 \\
222239 \\
224336\end{array}$ \\
\hline$x=a$ & $\begin{array}{l}\text { Markatos ef al (1984) } \\
\text { Le Quere (1991) } \\
\text { Preseat }\end{array}$ & $\begin{array}{l}0.021 \\
0.020\end{array}$ & $\begin{array}{l}0.0133 \\
0.120 \\
0.121\end{array}$ \\
\hline$N_{40}$ & $\begin{array}{l}\text { Markates of al (1984) } \\
\text { Le Quete (1951) } \\
\text { Present }\end{array}$ & $\begin{array}{l}16.523 \\
16.408\end{array}$ & $\begin{array}{l}32.045 \\
30.225 \\
29.819\end{array}$ \\
\hline
\end{tabular}

Table 2: Comparison of transitional flow with previous works for the square heated cavity with imposed temperatures.

\section{2) Conduction in a PCM}

The second comparison concerns the Stefan problem. The numerical results are compared with the analytical results (Figure 4) and show good agreements validating our approach.

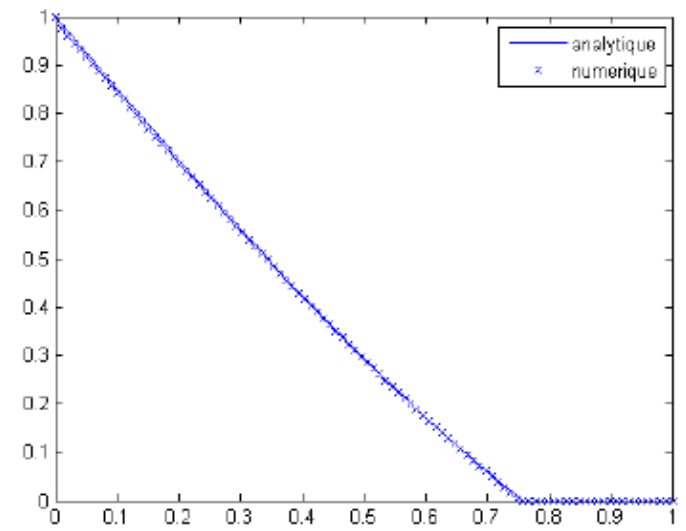

Figure 4: Comparison of results concerning the Stefan problem. 
3) Melting/freezing by natural convection in a PCM:

This work is the subject of a PhD thesis and is under progress.

\section{BIBLIOGRAPHY}

O. Bertrand, B. Binet, H. Combeau, S. Couturier, Y. Delannoy, D. Gobin, M. Lacroix, P. Le Quéré, M. Médale, J. Mencinger, H. Sadat and G. Vieira, Melting driven by natural convection, A comparison exercise: first results, Int. J. Therm. Sci. 38, p. 5-26 (1999).

J. Mencinger, Numerical simulation of melting in two-dimensional cavity using adaptative grid, Journal of Computational Physics 198, p. 243-264 (2004).

M.C. Sukop and D.T. Thorne, Lattice Boltzmann Modeling - An Introduction for Geoscientists and Engineers, Springer, 172p. (2006).

F. Kuznik, J. Vareilles, G. Rusaouen, G. Krauss, A double population Lattice Boltzmann method with non-uniform mesh for the simulation of natural convection in a square cavity, International Journal of Heat and Fluid Flow 28 (5), p. 862-870 (2007).

F. Kuznik, C. Obrecht, G. Rusaouen, JJ. Roux, LBM based flow simulation using GPU computing processor, Computers and Mathematics with Applications, In Press.

G. de Vahl Davis, Natural convection of air in a square cavity: a bench mark numerical solution. Int. J. Numer. Meth. Fluids 3, p. 249-264 (1983).

M. Hortmann, M. Peric, G. Scheuerer, Finite volume multigrid prediction of laminar natural convection: bench-mark solutions. Int. J. Numer. Meth. Fluids 11, p.189-207 (1990).

N. Markatos,C. Pericleous, Laminar and turbulent natural convection in an enclosed cavity. Int. J. Heat Mass Transfer 27, p.755-772 (1984).

P. Le Quere, Accurate solutions to the square thermally driven cavity at high Rayleigh number. Comput. Fluids 20, p.29-41 (1991). 


\section{AC3) MACRO-SCALE MODELLING}

\section{Heat transfers in wall including PCM: conduction and convection Frédéric KUZNIK \& Joseph VIRGONE \& Kevyn JOHANNES, Thermal Sciences Center of Lyon, France}

\section{INTRODUCTION}

This work deals with two mains heat transfer problems: the conduction in walls and the convection between wall and air. The main objective is the develop numerical modelling for the evaluation of PCM use in building walls.

The heat transfer problem by conduction in PCM wall has been investigated for the twenty past years, the first analytical approach being the Stefan problem. The main idea of our work is to study more precisely the stability of the numerical scheme and the spatial and time discretization errors.

The second topic concerns the evaluation of the convection heat transfer between a PCM panel and the air. Basically, the value of the convection coefficient is really important for the simulation of the energy efficiency of PCM walls. But, as most of the convection coefficient used are constant or correlations developed for isothermal walls, more precise values are needed. Then, we have developed both numerical simulation and experiment in order to develop and validate CFD models that can be used to calculate time dependant convection heat transfer coefficients.

\section{PHYSICAL MODEL}

\section{1) Conduction in PCM walls}

The 1D heat transfer equations is based on the equivalent heat capacity method (Kuznik et al., 2008; Kuznik and Virgone, 2009). The finite difference scheme is given for a node $i$ by:

$$
\rho_{i} C_{i}{ }_{i} \frac{T_{i}^{n+1}-T_{i}^{n}}{\Delta t}=-\lambda_{i}\left(\frac{T_{i-1}{ }^{n+1}-2 T_{i}^{n+1}+T_{i+1}{ }^{n+1}}{\Delta x^{2}}\right)
$$

The evolution system of $T_{i}$ can be written in the matrix form as:

$$
\{T\}^{n+1}=\left[M\left(\{T\}^{n}\right)\right]\left(\{T\}^{n}+\{B\}^{n+1}\right)
$$

with $\{T\}$ is the vector containing the node temperatures $T_{i,}[M]$ the matrix with temperature-dependent heat capacity of PCM and $\{B\}$ the vector containing external sollicitations.

Round-off errors appear during the calculation, then the stability is the growth of errors of the solution of the finitedifference numerical modeling. The stability conditions for the resolution of implicit and explicit linear finite-difference schemes are well known (Patankar, 1980). For the non-linear problems, it is difficult to find an analytical condition assuring the numerical stability of the solution. In literature [Koschen and Lehmann, 2004; Carbonari et al., 2006], stability conditions for linear schemes are often used for the non-linear ones. In our work, we demonstrate that stability conditions for linear problems are not sufficient to ensure the stability of the non-linear scheme. For that purpose, we use the following writing of the evolution system equation (0.1):

$$
\{T\}^{n+1}=\left\{R\left(\{T\}^{n}\right)\right\}
$$

\section{2) Convection coefficient}


For the calculation of the convection coefficient between the air and PCM wall, the following assumptions are used:

- 3D numerical modelling,

- 3D conduction in wall with equivalent heat capacity modelling,

- Incompressible Navier-Stokes equations with Boussinesq approximation,

- Non-stationnary calculations.

\section{COMPUTATIONAL PROCEDURE}

\section{1) Conduction in PCM walls}

The numerical scheme is a finite-difference explicit scheme. A home-made code is used for the resolution of the problem. The time and spatial steps depend on the spectral radius of $\{R\}$ Jacobian matrix to ensure the stability.

\section{2) Convection coefficient}

The commercial code STAR-CCM+ is used for the calculation of CFD. It is based on a finite-volume dscretization scheme.

\section{RESULTS \& DISCUSSION}

\section{1) Conduction in PCM walls}

The test case is given Figure 1.

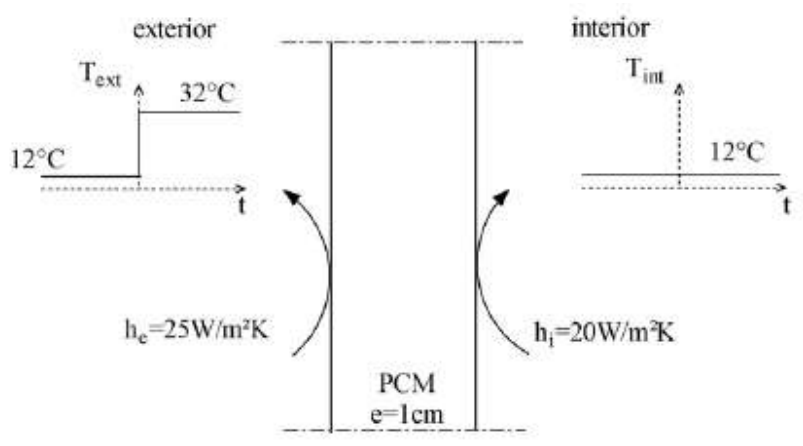

Figure 1: PCM panel test case

a) Stability

The stability analysis is based on the Jacobian matrix of $\{R\}$ given by:

$$
[K]=\left.\frac{\partial\{R(\{T\})\}}{\partial\{T\}}\right|_{\{T\}^{n}}
$$

If we use a linear scheme criteria, our implicit scheme is supposed to be unconditionally stable. Figure 2 shows the interior and exterior surface temperatures for two cases, $\rho$ being the spectral radius of $[K]$ :

- $|\rho([K])|=1.79$ (maximum value) for $\Delta t=3600 \mathrm{~s}$

- $|\rho([K])|=0.96$ (maximum value) for $\Delta t=100 \mathrm{~s}$ 

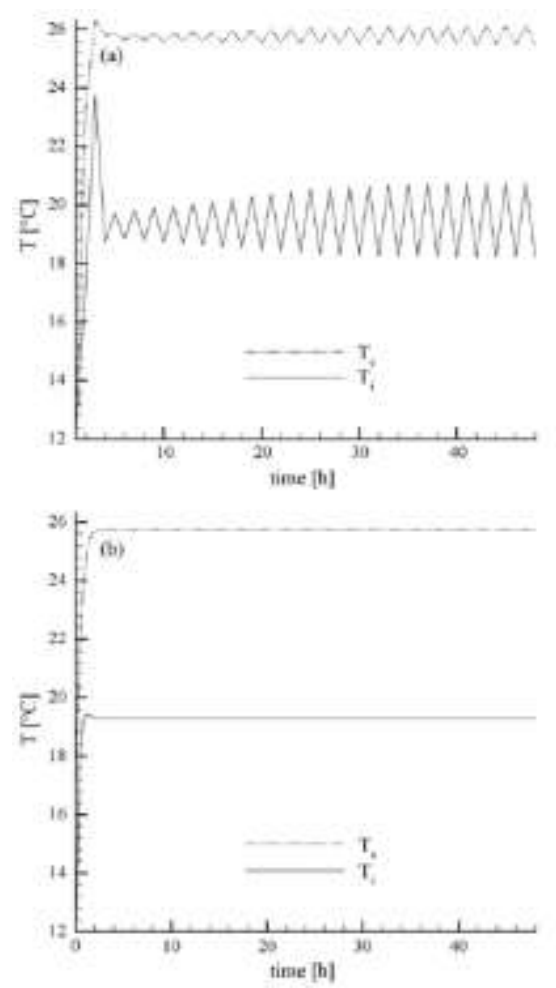

Figure 2: Interior and exterior surface temperatures Ti and Te for the case $|\rho([K])|=1.79$ (maximum value) (a) and $|\rho([K])|=0.96$ (maximum value) (b).

For the case (a), the numerical method is clearly not stable, whereas for the case (b), the stability is maintained. The scheme being non-linear, the stability conditions depend on the temperature values. The spectral radius of the Jacobian matrix allows to give a dynamic way to control the stability.

Our numerical algorithm is based on the stability criteria described previously. At each time step, $|\rho([K])|$ is calculated using the prescribed $\Delta t$. If the stability condition is not satisfied, the time step is reduced to fulfill the criteria. This method allows to avoid numerical instability during our simulations.

\section{b) Time discretization error}

In order to evaluate the time-scheme accuracy, the results obtained for a very small time step $\Delta t=0.01 \mathrm{~s}$ are used as "exact solution" and then relative errors on higher time step can be calculated. The relative error for the variable $T$ with exact solution $T_{\text {exact }}$ is calculated via:

$$
\text { relative error }=\max _{i, n}\left(\left|\frac{T_{i}^{n}-T_{\text {exact }, i}^{n}}{T_{\text {exact }, i}{ }^{m}-T_{\text {exact }, i} \min }\right|\right)
$$

where $T_{\text {exact }, i}{ }^{\max }$ and $T_{\text {exact, } i}{ }^{\min }$ are, respectively, the maximum and minimum values (according to time) of $T_{\text {exact }}$ at the position $i$.

Figure 3 shows the evolution of relative error with time step using surface temperatures for the comparisons. In order to reduce the error due to time discretization without having a too long computational cost, the time step chosen for our simulations is $60 \mathrm{~s}$. The relative error for this time step is less than the criteria of $1 \%$. 


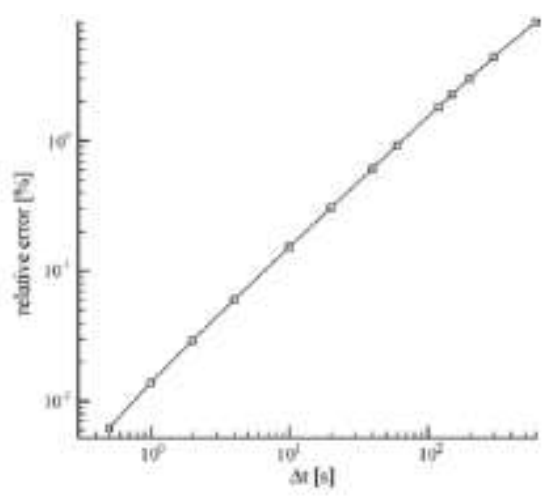

Figure 3: Evolution of relative error on temperature field with time step-case of walls with PCM.

\section{c) Spatial discretization error}

In order to evaluate the spatial-scheme accuracy, the results obtained for a very small mesh size $\Delta x=0.0000005 m$ are used as "exact solution" and then relative errors on higher mesh size can be calculated.

Figure 4 shows the evolution of relative error with mesh size. In order to reduce the error due to spatial discretization without having a too long computational cost, the mesh size chosen for our simulations is $0.0001 \mathrm{~m}$. The relative error for this mesh size is less than the criteria of $1 \%$. This low value of mesh size is due to the correct evaluation of temperature gradients according to the moving interface phenomena.

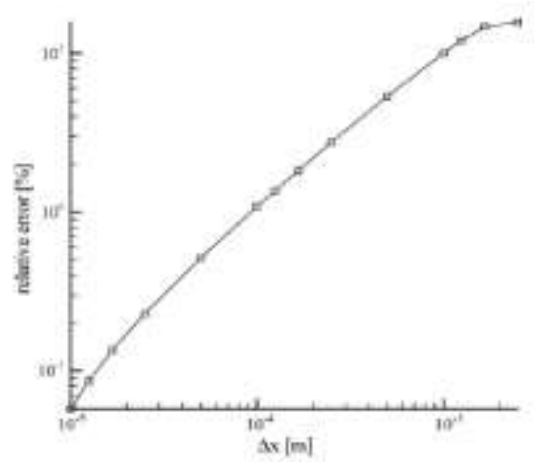

Figure 4: Evolution of relative error on temperature field with mesh size-case of PCM wall.

\section{2) Convection coefficient}

This work is the subject of a PhD thesis and is under progress. Figure 5 shows the first CFD results concerning the heat flux field near the wall. 


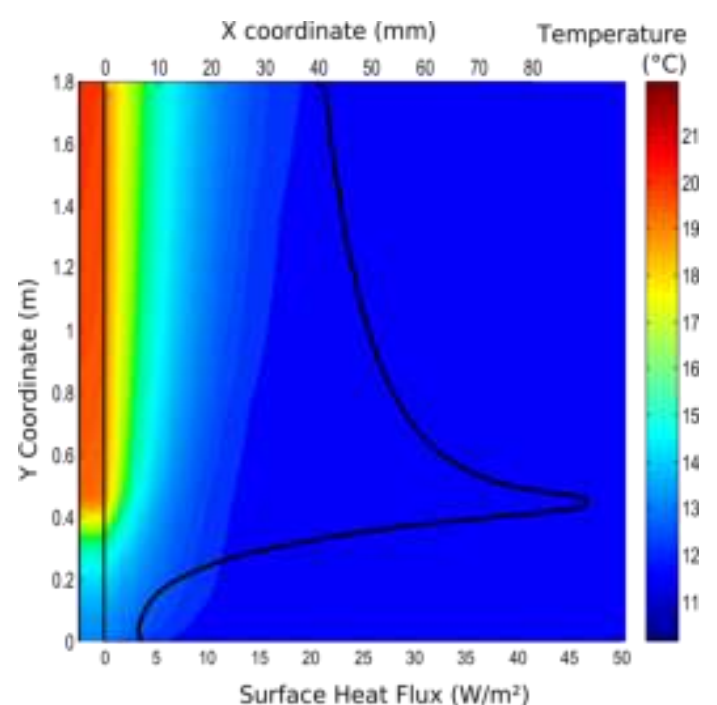

Figure 5: Convection heat transfer coefficient prediction using CFD

\section{BIBLIOGRAPHY}

F. Kuznik, J. Virgone, JJ. Roux, Energetic efficiency of room wall containing PCM wallboard: A full-scale experimental investigation. Energy and Buildings 40, p. 148-156 (2008).

F. Kuznik and J. Virgone, Experimental investigation of wallboard containing phase change material: Data for validation of numerical modeling. Energy and Buildings 41, p. 561-570 (2009).

S.V. Patankar, Numerical Heat Transfer and Fluid Flow, McGraw-Hill, Washington/New York/London, p. 197 (1980).

M. Koschenz, B. Lehmann, Development of a thermally activated ceiling panel with PCM for application in lightweight and retrofitted buildings, Energy and Buildings 36, p. 567578 (2004).

A. Carbonari, M. De Grassi, C. Di Perna, P. Principi, Numerical and experimental analyses of PCM containing sandwich panels for prefabricated walls, Energy and Buildings 38, p. 472-483 (2006). 


\section{Further investigation of enthalpy-porosity method in solid-liquid phase change}

H. SHMUELI \& G. ZISKIND, Heat Transfer Laboratory, Department of Mechanical Engineering, Ben-Gurion University of the Negev, Beer-Sheva 84105, Israel

\section{ABSTRACT}

Our research deals with a detailed study of solid-liquid phase change modeling by enthalpy method. In particular, we investigate the effect of mushy zone constant on the melting patterns and overall melting time. We also study the effect of velocity-pressure coupling and pressure discretization schemes on the numerical results, demonstrating that different schemes, that give practically identical pictures for single-phase problems, yield considerable differences when the phase change is involved. This effect is demonstrated in the present paper.

\section{INTRODUCTION}

In the enthalpy method, the energy equation is written using the enthalpy as a dependent variable along with the temperature, when the relationship between the two is known. Early formulation of the method was introduced by Shamsundar and Sparrow [1], who showed that the modified equation was equivalent to the conventional energy equation written using the temperature as the sole dependent variable in the classical formulation of the "conduction" phase change. Voller et al. [2] developed an enthalpy formulation for convection/diffusion phase change, which requires mass and momentum conservation equations in addition to the energy conservation equation. Moreover, the method of Voller et al. [2], extended by Voller and Prakash [3], is applicable for melting over a range of temperatures: the "mushy" zone, i.e. the region where both liquid and solid phases present, is modelled by mimicking a porous medium with the liquid fraction as its "porosity." For this reason, the method uses the Carman-Koseny equation and is commonly termed the enthalpy-porosity formulation. The momentum equation, presented below contains a source term which depends on the current liquid fraction, $\square$, and on a certain constant $A_{m u s h}$. When the local liquid fraction equals zero - meaning that the material is solid at this location - the source term becomes very large and the velocity diminishes to zero.

In our ongoing experimental and numerical investigation, the effect of the mushy zone constant $A_{\text {mush }}$ is thoroughly investigated. In the present paper, different velocity and pressure discretization schemes are explored, and their effects are discussed.

\section{PHYSICAL MODEL}

Our investigation deals with melting in a cylindrical vertical tube. The tube diameter is $30 \mathrm{~mm}$, and the temperature difference between the outer wall of the tube and the melting temperature is $30^{\circ} \mathrm{C}$. The working material is defined based on a commercially available paraffin wax with melting temperature range of $28-30^{\circ} \mathrm{C}$. The initial height of the solid material in the tube is $17 \mathrm{~cm}$.

\section{COMPUTATIONAL PROCEDURE}

As usual for phase-change problems, we solve the momentum equation in the form:

$$
\frac{\partial}{\partial t}(\rho \vec{v})+\nabla \cdot(\rho \vec{v} \vec{v})=-\nabla p+\nabla \cdot(\tau)+\rho \vec{g}+\vec{F}
$$

where

$$
\vec{F}=\frac{(1-\beta)^{2}}{\beta^{3}+\varepsilon} A_{m u s h} \vec{v}
$$


The mushy zone constant $A_{\text {mush }}$ is set equal to $10^{8}$, but other values have been also checked. We would like to leave the question of the appropriate value of $A_{\text {mush }}$ outside this discussion, as the problem which we have now is persistent for other values, as well.

\section{RESULTS \& DISCUSSION}

It appears that the time to complete melting may be affected by the different calculation schemes used. In particular, we tried such schemes as PISO and SIMPLE for pressurevelocity coupling, and Body-Force-Weighted and PRESTO! for pressure discretization.

Figure 1 shows the melt fraction vs. time for three different combinations of the abovementioned schemes:

1. PISO and Body-Force-Weighted

2. SIMPLE and PRESTO!

3. PISO and PRESTO!

One can see that while no difference was found between PISO and SIMPLE, a significant difference is observed between PRESTO! and Body-Force-Weighted schemes.

Table 1 contains pictures of melting for the different schemes at various instants. One can see that the calculation techniques are also responsible for the shape of the solid paraffin. For comparison, the experimentally obtained melting pattern at 10 minutes is also shown.

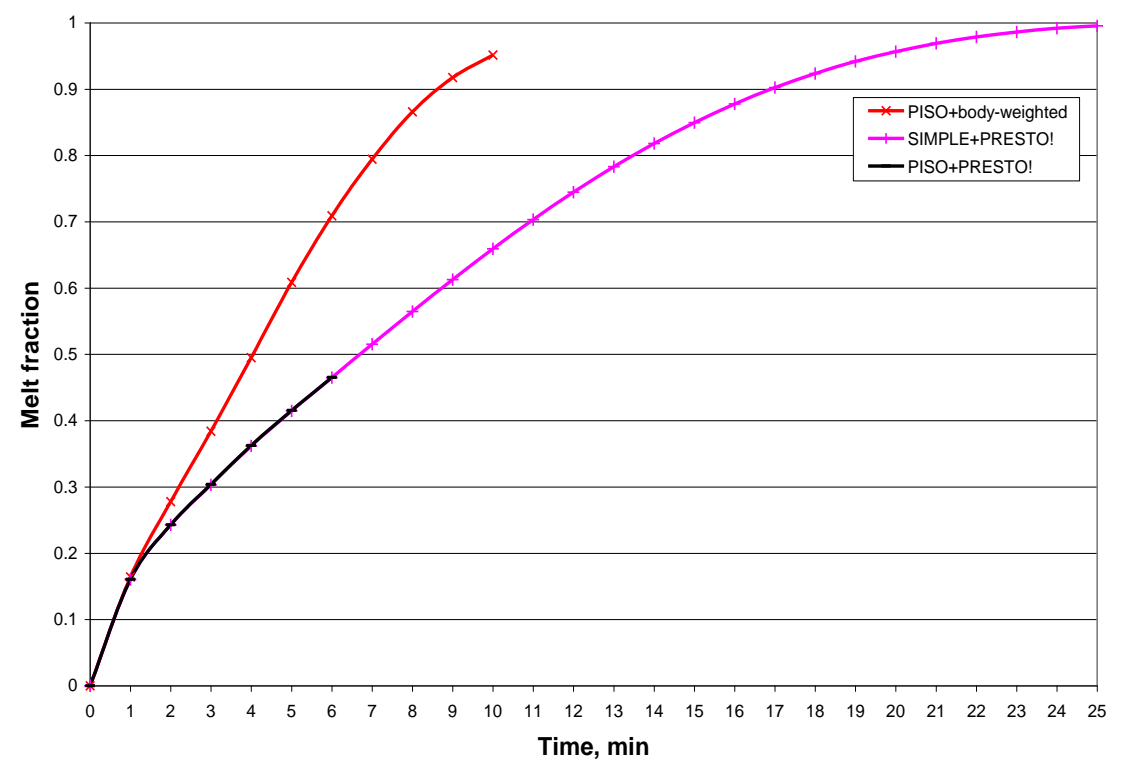

Figure 1: Melt fraction vs. time for three different combinations. 
Table 1: Pictures of melting for the different schemes at various instants.

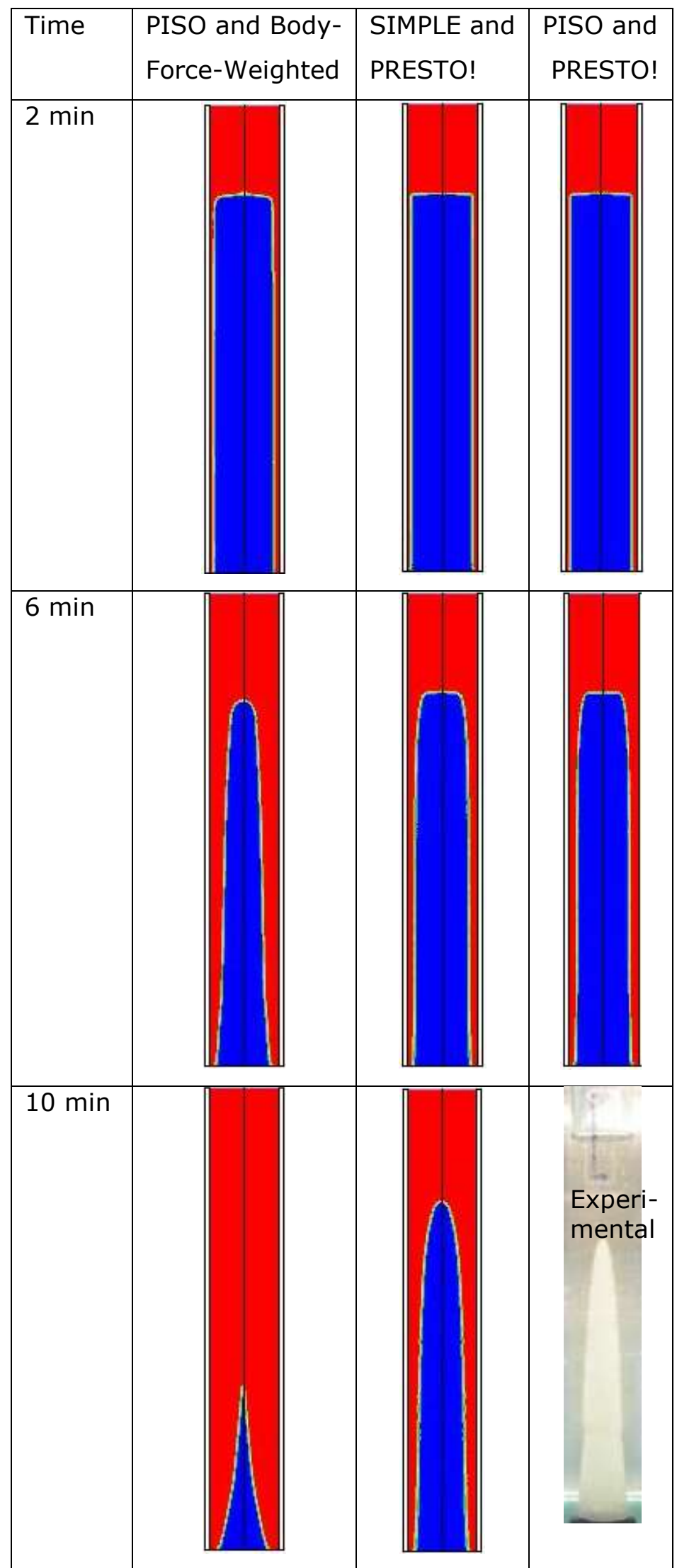


In order to localize the source of these differences, we tried a model in which the same boundary conditions were applied to a tube filled with liquid paraffin in the otherwise identical system. Thus, the phase change was canceled and a transient natural convection problem was solved. PRESTO! and Body-Force-Weighted schemes were investigated whereas the pressure-velocity coupling scheme was PISO.

Figure 2 presents the change of the average temperature of the liquid with time. One can see that there is no difference between the schemes in a transient single-phase problem. Therefore, we conclude that the difference encountered in the melting problem is caused by some feature related to the phase-change modeling.

Natural convection

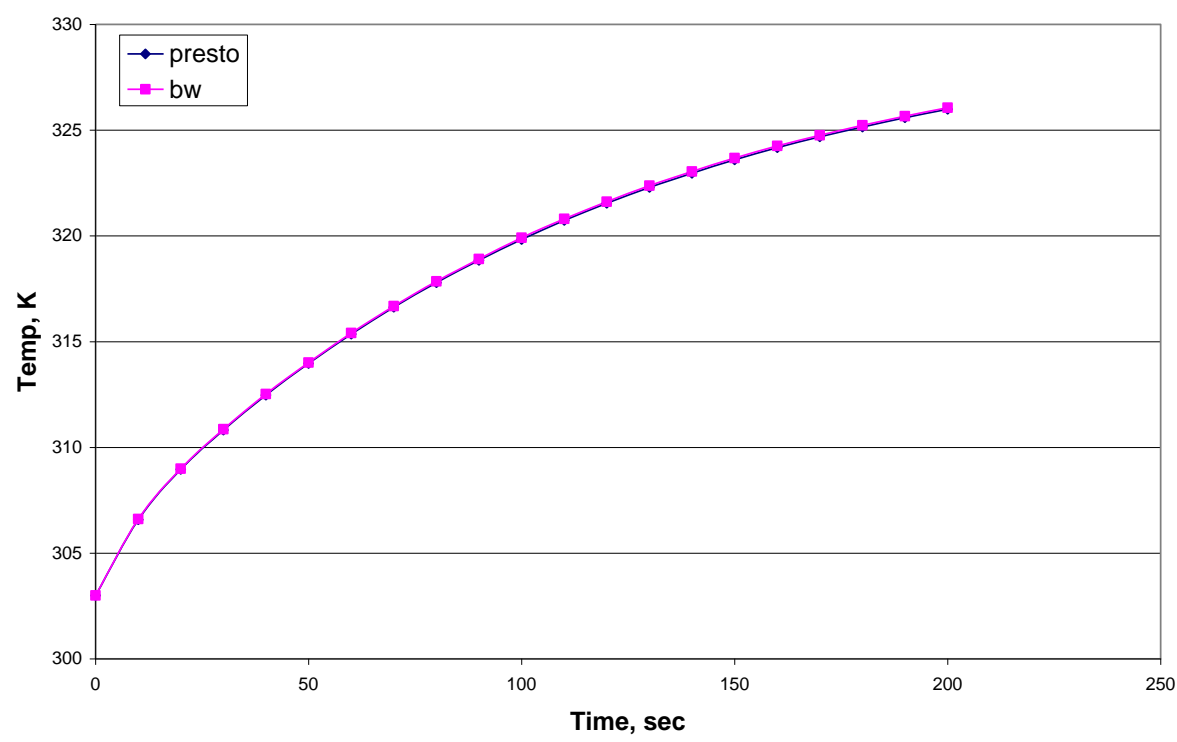

Figure 2: Mean temperature vs. time in transient natural convection only.

The vector flow fields for the two above-mentioned schemes are shown in Table 2. One can see that the images are quite similar, pointing that the differences between the schemes have nothing to do with natural convection. Thus, we conclude that modeling of the mushy region needs further investigation. 
Table 2: Vector flow fields for Body-Force Weighted and PRESTO! schemes.

\begin{tabular}{|c|l||l||l|l||}
\hline Time & \multicolumn{2}{|l|}{$\begin{array}{l}\text { PISO and Body- } \\
\text { Force Weighted }\end{array}$} & \multicolumn{2}{|c|}{ PISO and } \\
PRESTO!
\end{tabular}

\section{BIBLIOGRAPHY}

[1] Shamsundar, N. and Sparrow, E.M., Analysis of Multidimensional Conduction Phase Change via the Enthalpy Model, ASME J. Heat Transfer 97, pp. 333-340, 1975.

[2] Voller, V.R., Cross, M. and Markatos, N.C., An Enthalpy Method for Convection/Diffusion Phase Change, Int. J. Numerical Methods in Engineering 24, pp. 271-284, 1987.

[3] Voller, V.R. and Prakash, C., A Fixed Grid Numerical Modeling Methodology for Convection-Diffusion Mushy Region Phase-Change Problems, Int. J. Heat and Mass Transfer 30, pp. 1709-1719, 1987. 
PCM simulation for HVAC systems

Motoi YAMAHA, Chubu University, Japan.

\section{INTRODUCTION}

Our research group has developed macro scale simulation models for ice and PCM storage system for HAVC systems. The objectives of models are to evaluate system performance of HVAC system with PCM storage. For ice storage, we had developed models for an ice tank with ice making coils and slurry ice storage. For PCM storage, an air distribution system with PCM in air ducts and a water tank contains PCM capsules are simulated.

The effect of various design conditions, such as heat load profile, quantity of materials, or melting temperature is evaluated.

\section{PHYSICAL MODEL}

The physical models are based on one-dimensional heat transfer equation. The basic equation is:

$$
(1-I P F) \frac{\partial \theta}{\partial t}+u \frac{\partial \theta}{\partial z}=\frac{\lambda}{\rho c} \frac{\partial^{2} \theta}{\partial z^{2}}-\frac{q}{\rho c}
$$

\section{NOMENCLATURE}

\section{C specific heat $[\mathrm{J} /(\mathrm{kg} * \mathrm{~K})]$}

IPF Ice Packing Factor: a ratio of volume of ice or PCM to a tank volume [-]

$q \quad$ volumetric heat flow from PCM $\left[\mathrm{W} / \mathrm{m}^{3}\right]$

$t \quad$ time [s]

$u \quad$ velocity of heat transfer medium $[\mathrm{m} / \mathrm{s}]$

$z \quad$ length for flow direction [m]

$\theta \quad$ temperature [K]

$\lambda \quad$ thermal conductivity $[\mathrm{W} /(\mathrm{m} * \mathrm{~K})]$

$\rho$ density $\left[\mathrm{kg} / \mathrm{m}^{3}\right]$

\section{ICE STORAGE}

A simulation method was developed considering temperature profile of water in a tank and heat transfer between ice surface and water [1].

\section{PCM STORAGE}

To evaluate PCM storage, macro scale simulation model was developed using enthalpy method that treats latent heat as variation of specific heat by temperature [2].

\section{BIBLIOGRAPHY}

[1] Studies on thermal characteristics of ice thermal storage tank and a methodology for estimation of tank efficiency.

Motoi Yamaha, Nobuo Nakahara and Rie Chiba. International Journal of Energy Research, 32, 226-241.

[2] The Evaluation of Peak Shaving by a Thermal Storage System Using Phase Change Materials in Air Distribution Systems.

Motoi Yamaha and Shinya Misaki. ASHRAE HVAC\&R Research, Vol. 12, No. 3c, pp. 861-870. 
Characterization of melting and solidification in a real scale PCMair heat exchanger: Numerical model and experimental validation Pablo DOLADO, A. LAZARO, J.M. MARIN and B. ZALBA, University of Zaragoza, Spain.

\section{INTRODUCTION}

A model has been developed to simulate the performance of a Thermal Energy Storage unit in a real scale PCM-air heat exchanger, analyzing the heat transfer between the air and a commercially available and slab macroencapsulated PCM. The model is based on one-dimensional conduction analysis, utilizing finite differences method, and implicit formulation, using the thermo-physical data of the PCM measured in the laboratory: enthalpy and thermal conductivity as functions of temperature. The model can take into account the hysteresis of the enthalpy curve and the convection inside the PCM, using effective conductivity when necessary. Two main paths are followed to accomplish the modeling: the thermal analysis of a single plate, and the thermal behavior of the entire TES unit. Comparisons between measurements and simulations are undertaken to evaluate the models. Average errors of less than $12 \%$ on thermal power are obtained for the entire cycle.

\section{PHYSICAL MODEL}

The basis model assumed only conduction heat transfer inside the PCM plate, in a normal direction to the air flow. The model analyzed the temperature of the airflow in a onedimensional way. Due to its symmetry, the analyzed system was a division of the prototype.
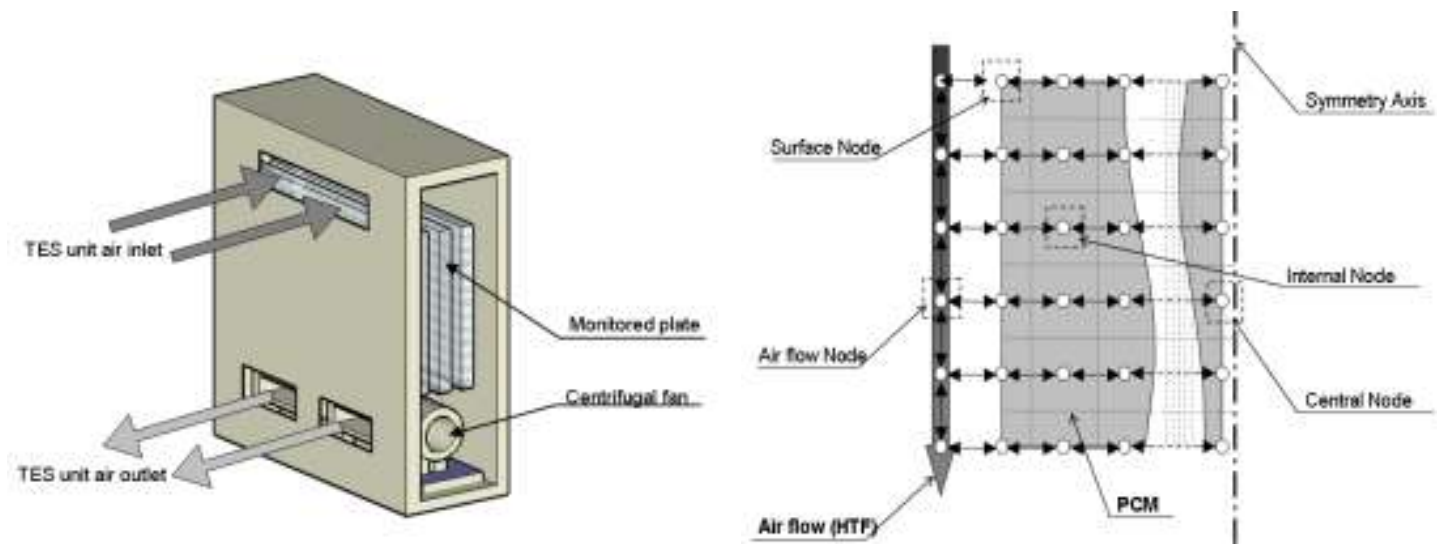

The storage unit (left) and the nodal distribution in the 1D plate system (right)

\begin{tabular}{|c|c|}
\hline Nodes & Equations \\
\hline Air Flow & $T_{\text {air }}=T_{\text {air }-1}-N T U_{\text {air }}\left(T_{\text {air }-1}-T_{\text {surface }}\right)$ \\
\hline Air Surface & $T_{\text {suffuce }}=\left[T_{\text {surface }}^{t-1}+2\left(F o_{\text {enc }} T_{\text {enc }}+F o_{\text {enc }} B i_{\text {enc }} T_{\text {air }}\right)\right] /\left[1+2\left(F o_{\text {enc }} B i_{\text {enc }}+F o_{\text {enc }}\right)\right]$ \\
\hline $\begin{array}{l}\text { Surface } \\
\text { Encapsulation }\end{array}$ & $T_{\text {enc }}=\left[T_{\text {enc }}^{t-1}+2\left(F o_{\text {enc }-P C M} T_{\text {sufface }}+2 F o_{P C M-\text { enc }} T_{\text {enc }}\right)\right] /\left[1+2\left(F o_{\text {enc }-P C M}+2 F o_{P C M-e n c}\right)\right]$ \\
\hline $\begin{array}{l}\text { Encapsulation } \\
\text { PCM }\end{array}$ & $T_{P C M}=\left[T_{P C M}^{t-1}+F o_{P C M}\left(2 T_{e n c}+T_{P C M+1}\right)\right] /\left(1+3 F o_{P C M}\right)$ \\
\hline PCM Inner & $T_{P C M}=\left[T_{P C M}^{t-1}+F o\left(T_{P C M-1}+T_{P C M+1}\right)\right] /(1+2 F o)$ \\
\hline PCM Central & $T_{P C M}=\left(T_{P C M}^{t-1}+2 F o T_{P C M-1}\right) /(1+2 F o)$ \\
\hline
\end{tabular}




\section{COMPUTATIONAL PROCEDURE}

A PCM plate model was developed with finite differences, one-dimensional, implicit formulation. Implicit formulation was selected because of its unconditional stability. In the present work, the model was implemented in Matlab R2008b. The software implements direct methods (variants of Gaussian elimination) through the matrix division operators, which can be used to solve linear systems.

\section{RESULTS \& DISCUSSION}

The thermal power obtained for a full cycle experiment and its corresponding simulation are shown in the next figure.

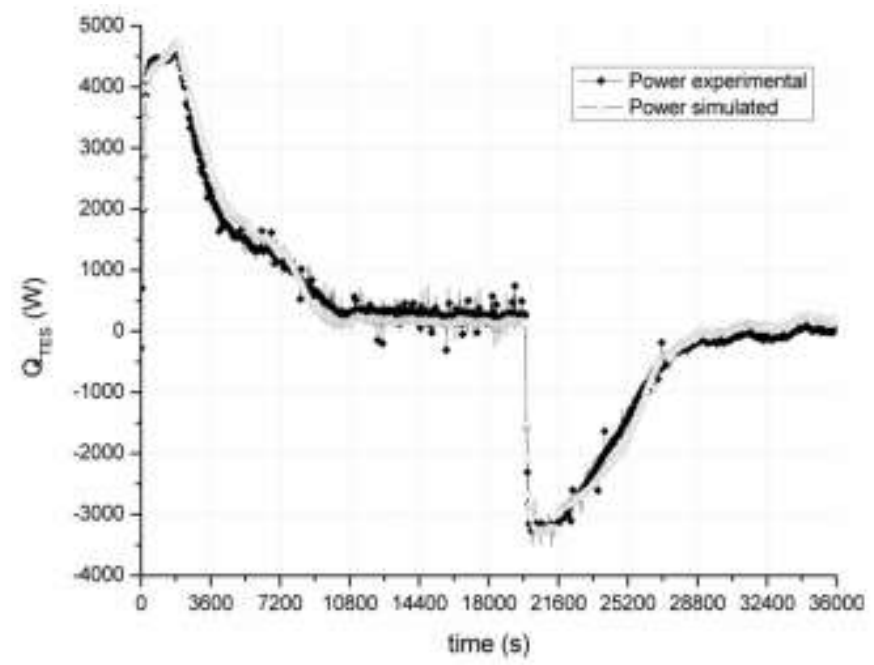

Full cycle comparison results between experiment and simulation

The average difference between measurements and simulations was $160 \mathrm{~W}$, although differences of up to $400 \mathrm{~W}$ were found in specific locations of the curve.

To quantify the difference between experimental data and simulated results, the relative maximum error and an average error were used as indicated in the equations:

$$
\begin{aligned}
& \operatorname{RME}(\%)=\max _{1,2, \ldots, N}\left\{\left|\frac{y_{\exp }-y_{\text {sim }}}{y_{\exp }}\right| \times 100\right\} \\
& \text { Average } \operatorname{Error}(\%)=\sum_{1,2, \ldots, N}\left\{\left|\frac{y_{\exp }-y_{\text {sim }} \mid}{y_{\exp }}\right| \times 100\right\} / N
\end{aligned}
$$

The RME was always less than $15 \%$ for the low temperature cases $\left(<40^{\circ} \mathrm{C}\right)$. For the other cases, specific errors of up to $30 \%$ could be found when the PCM in the TES unit was almost melted at low power rates. However, the average error for the melting process was less than $12 \%$ in all cases; furthermore, for the low temperature cases the average error was less than $4 \%$.

\section{CONCLUSIONS}

- A model was developed and experimentally validated to test the thermal behavior of a TES unit consisting of a PCM-air heat exchanger.

- The model was based on one-dimensional conduction analysis, utilizing finite differences method, and implicit formulation. The phase change process was described by means of the $h(T)$ curve. 
- As the effect of hysteresis phenomenon on the TES unit thermal performance can be substantial, it has been included in the model and considered for the PCM enthalpytemperature curve.

- Natural convection within the liquid PCM has been considered in the model by means of the effective thermal conductivity.

- The model is theoretically valid for every air flow under internal forced convection and it was experimentally validated for an airflow range from 0.7 to $2.1 \mathrm{~m} / \mathrm{s}$ and for an inlet air temperature range from 8 to $45^{\circ} \mathrm{C}$. As the model is one-dimensional, the L/e ratio of the PCM slabs must be over 10 to ensure a negligible 2D conduction.

- From the comparison between simulations and experimental results it was concluded that to determine the thermal behavior of the TES unit, thermal simulation of the PCM encapsulation was not necessary. This happened in this specific study case due to the relationship between the main thermal resistances in the process. However, it is mandatory to take into account the rugosity of the encapsulation, as rugosity is related to the calculation of heat transfer between the air and the PCM slabs.

\section{NOMENCLATURE}

$N T U_{\text {air }}=(h \cdot \Delta x \cdot w) / C_{\text {air }}:$ number of transfer units

$\mathrm{T}\left[{ }^{\circ} \mathrm{C}\right]$ : temperature

$\mathrm{y}_{\mathrm{exp}}, \mathrm{y}_{\text {sim: }}$ : experimental or simulated value, respectively

$\mathrm{N}$ : number of elements

RME: Relative Maximum Error

Bi: Biot number

Fo: Fourier number

$$
\begin{aligned}
& \mathrm{Fo}_{\text {enc }}=\frac{\lambda_{e n c} \cdot \Delta t}{\rho_{e n c} \cdot C p_{e n c} \cdot e^{2}} \\
& \mathrm{Fo}_{\mathrm{PCM}}=\frac{\lambda_{P C M}(T) \cdot \Delta t}{\rho_{P C M}(T) \cdot C p_{P C M}(T) \cdot \Delta y^{2}} \\
& \mathrm{Fo}_{\mathrm{PCM}-\mathrm{enc}}=\frac{\lambda_{P C M} \cdot \Delta t}{\left(\rho_{e n c} \cdot C p_{e n c} \cdot e+\rho_{P C M} \cdot C p_{P C M} \cdot \Delta y\right) \cdot \Delta y} \\
& \mathrm{Fo}_{\text {enc-PCM }}=\frac{\lambda_{e n c} \cdot \Delta t}{\left(\rho_{e n c} \cdot C p_{e n c} \cdot e+\rho_{P C M} \cdot C p_{P C M} \cdot \Delta y\right) \cdot e} \\
& \mathrm{Bi}_{\text {enc }}=\frac{h_{a i r} \cdot e}{\lambda_{e n c}}
\end{aligned}
$$

\section{ACKNOWLEDGEMENT}

This work has been carried out in the frame of the research projects ENE2005-08256C02-02 (Implementation and analysis of thermal energy storage with phase change materials for air conditioning applications) and ENE2008-06687-C02-02 (Contribution of the thermal energy storage to the energetic efficiency of buildings and industrial applications), both funded by the Spanish Government.

\section{BIBLIOGRAPHY}

[1] A. Lazaro, P. Dolado, J.M. Marín \& B. Zalba, PCM-air heat exchangers for freecooling applications in buildings: Experimental results of two real-scale prototypes, Energy Conversion and Management, vol. 50 (2009), no. 3, pp. 439443.

[2] A. Lazaro, P. Dolado, J.M. Marin \& B. Zalba, PCM-air heat exchangers for freecooling applications in buildings: Empirical model and application to design, Energy Conversion and Management, vol. 50 (2009), no. 3, pp. 444-449. 
[3] C. Arkar, S. Medved, Influence of accuracy of thermal property data of a phase change material on the result of a numerical model of a packed bed latent heat storage with spheres, Thermochimica Acta, vol. 438 (2005), no. 1-2, pp. 192-201.

[4] M. Zukowski, Mathematical modeling and numerical simulation of a short term thermal energy storage system using phase change material for heating applications, Energy Conversion and Management, vol. 48 (2007), no. 1, pp. 155165.

[5] J. Bony. \& S. Citherlet, Numerical model and experimental validation of heat storage with phase change materials, Energy and Buildings, vol. 39 (2007), no. 10, pp. 1065-1072. 


\title{
AC4) MULTI-SCALE APPROACH
}

\author{
A TRNSYS Type for the Simulation of Building Wall Containing PCM \\ Frédéric KUZNIK \& Joseph VIRGONE \& Kevyn JOHANNES, Thermal Sciences Center of \\ Lyon, France.
}

\section{INTRODUCTION}

The use of PCM in building walls is a way to store latent heat energy, as well as sensible energy: from a phenomenological point of view, the thermal inertia of the building is then passively enhanced. Light weight buildings tend to undergo large temperature fluctuations due to external cooling or heating loads. Using PCM materials in such buildings allows to reduce notably temperature fluctuations (Schossig et al., 2005; Shilei et al., 2006; Kuznik et al., 2008).

PCM has enormous potential for energy saving. However, many materials with various mixtures exist, as well as many configurations of PCM integration in the building envelop(Hauer et al., 2005). An optimization of PCM is then necessary, considering the building components and the geographical location. This work can be done using numerical simulations. Actually, building energy simulations tools are numerous: BLAST, BSim, DeST, DOE, ECOTECT, Ener-Win, Energy Express, Energy-10, EnergyPlus, eQUEST, ESP-r, IDA-ICE, IES, HAP, HEED, PowerDomus, SUNREL, Tas, TRACE, TRNSYS,...The TRNSYS tool is chose for our work because of the possibility to connect the building with many other systems (HVAC, renewable energy) and its numerous validations.

Even if the physical equations for the PCM are well known, only few numerical models exist. Most of the numerical models concern the entire building modeling: Koschenz and Lehmann, 2004; Darkwa and O'Callaghan, 2006; , Zhou et al., 2008; Halford et al. , $2007 ; \ldots$ These models consider an unidirectional heat transfer in walls and a air energy balance equation to calculate the mean room air temperature. Then, these models cannot be adapted easily to any building configuration. Moreover, the PCM energy storage can be enhanced if coupled with HVAC systems (for example nighttime ventilation in summer for free-cooling), requiring a modular simulation tool structure.

A first approach for the simulation of PCM walls using TRNSYS lies in the work of Ibanez et al., 2005. Their modeling does not aim a simulation of the real transfer process. The storage and release effects of PCM are simulated using the active layer tool in TRNSYS. The PCM procedure is a controller: the inputs are temperatures (wall and air) and the outputs the data for the active layer in order to simulate the PCM effect from an energetic point of view. This procedure allows to evaluate the global influence of PCM in the whole energy balance of a room, but more experimental validations are nedded.

In the work of Ahmad et al., 2006, a model of the Helsinki University of Technology has been adapted to be used as a PCM wall in TRNSYS. This model consits of 729 nodes, 9 nodes in each direction of the wall. The high node number slows down the simulations. Moreover, the specific heat capacity is fixed to a top hat temperature function.

In this work, a TRNSYS type is presented and validated through experimental results obtained by our test cells MINIBOITE.

\section{COMPUTATIONAL PROCEDURE}

One of the main problems was to associate the PCM modeling inside TRNSYS environment. So we decided to link our model to type 56, the well known multizone building type, like it has been made for the "slab on grade" type in the TESS library (cf. ref TRNSYS documentation). The Figures 1, 2 and 3 show the implementation principle of the type within TRNSYS. 


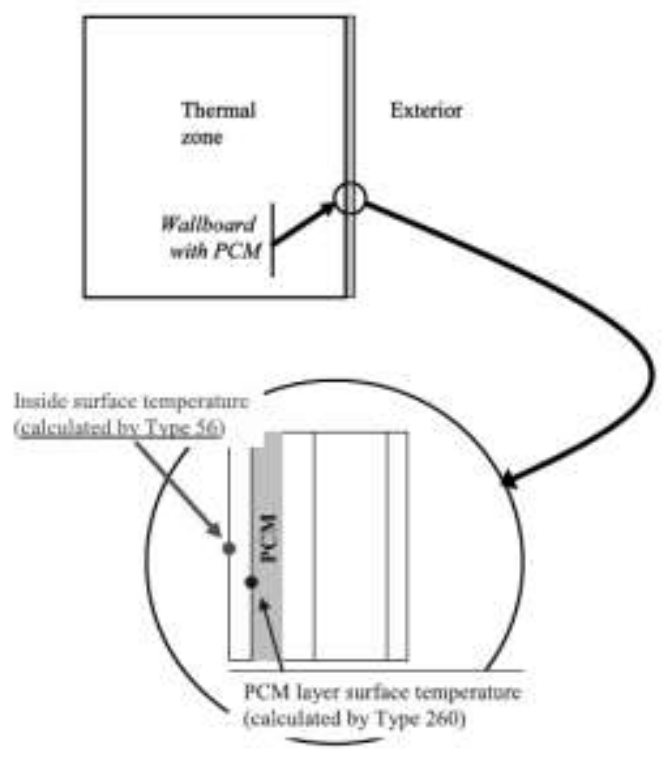

Figure 1: Practical implementation of the PCM type

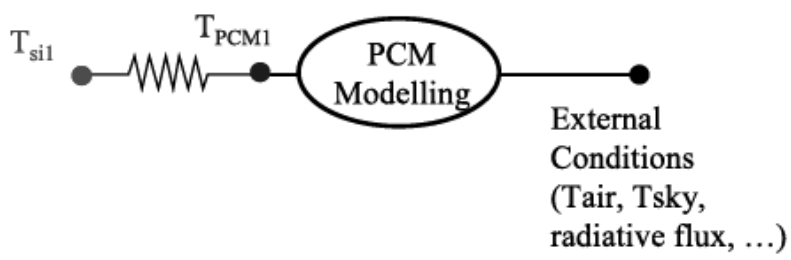

Figure 2: Schematic PCM type.

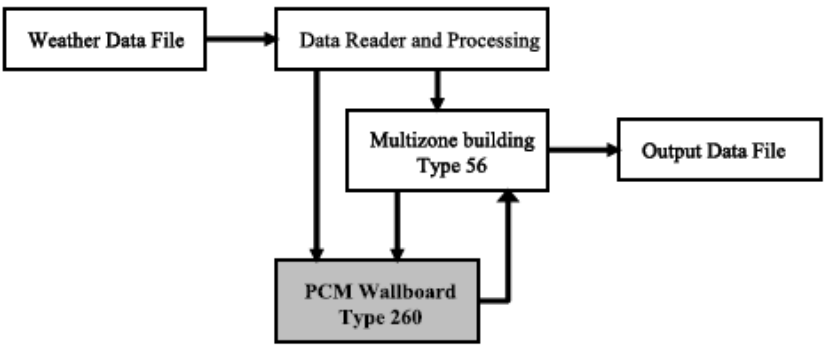

Figure 3: TRNSYS flow diagram with PCM type

The principles of the connexion between Type 56 and the PCM type are as follows (Figure 3):

- The inside surface temperature, calculated by the type 56 , is used as an input for the PCM type.

- The other inputs are the external conditions like temperature, solar heat flux (short wave radiation), ambient temperature and view factor (Iong wave radiation).

- The global conductance of the layers situated between the thermal zone and the PCM layer is a parameter of the type.

- The layers situated between the PCM and the exterior, with a maximum of 4, are parameters of the type (thickness, physical properties, number of mesh nodes).

- The last parameters are the properties of the PCM:

- Temperatures and the corresponding heat capacity

- Solid and liquid thermal conductivities. 
The basic equations are those described in the section Ac3) (Kuznik et al., 2008).

\section{COMPUTATIONAL PROCEDURE}

The new Type 260 is linked to the building Type 56. The time step and spatial steps can be modified and are chosen so that the error can be accepatable (Kuznik et al., 2008). The resolution of the entire system is done by TRNSYS iteration procedure.

\section{RESULTS \& DISCUSSION}

The experimental results concern two identical boxes with and without PCM. The external sollicitations are temperature step and sinusoidal external temperature evolution. The data can be found in Kuznik and Virgone 2009.

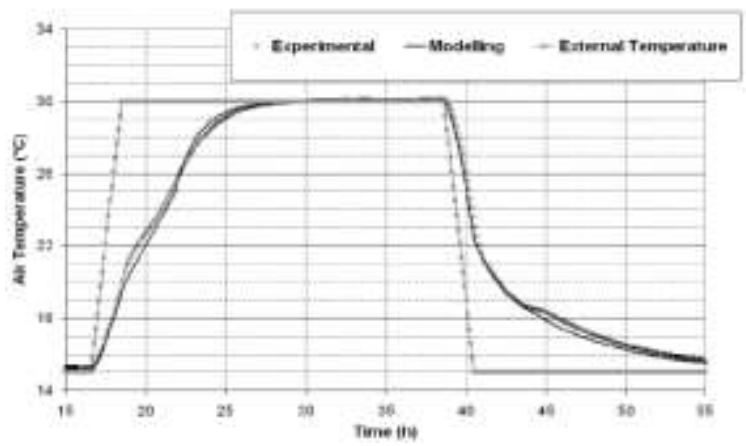

Figure 4: Comparison of simulated and measured indoor temperature of the test cell with PCM: two hours increase/decrease external temperature.

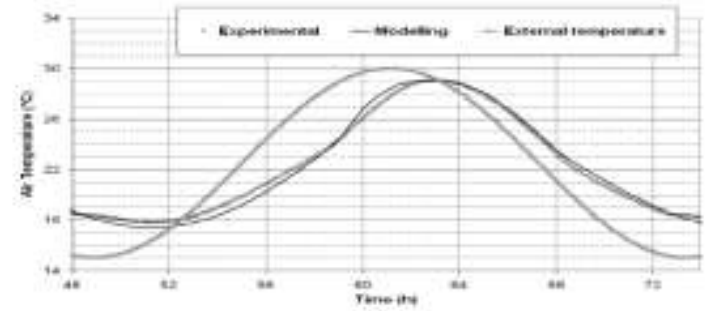

Figure 5: Comparison of simulated and measured indoor temperature of the test cell with PCM: sinusoidal external temperature.

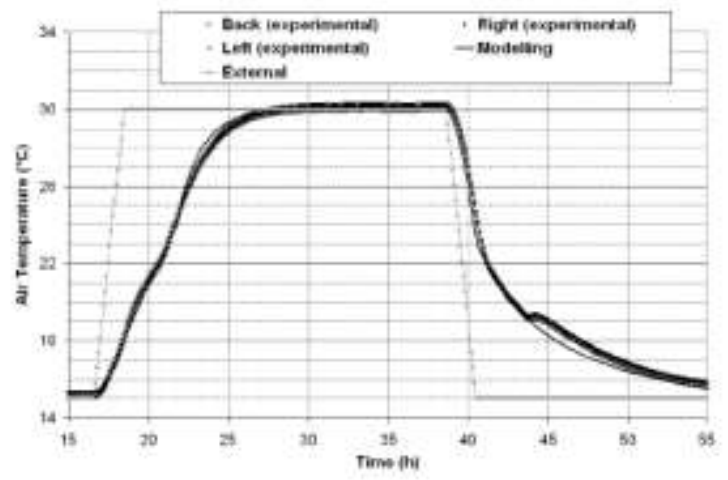

Figure 6: Comparison of simulated and measured inside vertical surface temperatures of the test cell with PCM: two hours increase/decrease external temperature. 


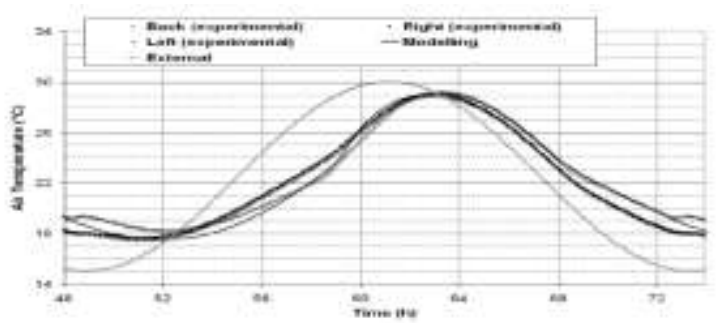

Figure 7: Comparison of simulated and measured inside vertical surface temperatures of the test cell with PCM: sinusoidal external temperature.

In the both cases, we obtain a very good agreement between simulation and measurements (see Figure 14 15). In the case of the linear solicitation, the PCM type allows to reproduce accurately the air temperature evolution. But during the temperature decrease, we see that our model can not render exactly the phenomena of temperature stabilization that occurs at time $=45$ hours which is due to the freezing of PCM microcapsules. In the case of the sinusoidal solicitation, the simulation gives good results. The difference between measurement and simulation is always under $1^{\circ} \mathrm{C}$.

Figure 6 and 7 present the indoor surface temperature of the cell vertical wallboards. The agreement between measured and computed values is good especially in the case of the temperature linear solicitation. In the case of the sinusoidal solicitation, one can see some differences according to the wall in consideration. Indeed, in the measured values we observe a sensitive difference between the side wall and the back wall. The measured obtained with our type give a good representation of the measured values. However in this case, the presence of PCM involves aeraulic effects that our model is not able to reproduce. The model gives the same results for the three vertical wallboards of the cell.

The TRNSYS Type developed in our study allows to predict the temperature evolution in an encolsure with PCM walls. It can now be used to test systems and optimize the physical properties of PCM.

\section{BIBLIOGRAPHY}

P. Schossig, H.M. Henning, S. Gschwander, T. Haussmann, Micro-encapsulated phasechange materials integrated into construction materials, Solar Energy Materials and Solar Cells 89, p. 297-306 (2005).

L.V. Shilei, Z. Neng,F. Guohui, Impact of phase change room on indoor thermal environment in winter. Energy and Buildings 38, p.18-24 (2006).

F. Kuznik, J. Virgone, JJ. Roux, Energetic efficiency of room wall containing PCM wallboard: A full-scale experimental investigation. Energy and Buildings 40, p. 148-156 (2008).

A. Hauer, H. Mehling, P. Schossig, M. Yamaha, L. Cabeza, V. Martin, F. Setterwall, Annex 17: Advanced Thermal Energy Storage through Phase Change Materials and Chemical Reactions - Feasibility Studies and Demonstration Projects. Final Report of International Energy Agency (2005).

M. Koschenz, B. Lehmann, Development of a thermally activated ceiling panel with PCM for application in lightweight and retrofitted buildings, Energy and Buildings 36, p. 567578 (2004).

K. Darkwa, P.W. O'Callaghan, Simulation of Phase Change Drywalls in a Passive Solar Building. Applied Thermal Engineering 26, p. 853-858 (2006).

G. Zhou, Y. Zhang, K. Lin, W. Xiao, Thermal analysis of a direct-gain room with shapestabilized PCM plates. Renewable Energy 33, pp. 1228-1236 (2008).

C.K. Halford, R.F. Boehm, Modeling of Phase Change Material Peak Load Shifting. Energy and Buildings 39, p. 298-305 (2007). 
M. Ibanez, A. Lazaro, B. Zalba, L.F. Cabeza, An approach to the simulation of PCMs in building applications using TRNSYS. Applied Thermal Engineering 25, p. 1796-1807 (2005).

M. Ahmad, A. Bontemps, H. Sallee, D. Quenard, Thermal Testing and Numerical Simulation of a Prototype Cell using Light Wallboards coupling Vacuum Isolation Panels and Phase Change Material. Energy and Buildings 38, p. 673-681 (2006).

F. Kuznik and J. Virgone, Experimental investigation of wallboard containing phase change material: Data for validation of numerical modeling. Energy and Buildings 41, p. 561-570 (2009). 


\section{AC6) REACTOR MODELS}

\section{A Photovoltaic panel coupled with a phase changing material heat storage system in hot climates \\ Valerio Lo BRANO \& Giuseppina CIULLA, University of Palermo, Italy}

\section{INTRODUCTION}

Nowadays, there is a great impulse in the field of photovoltaic cell systems (PV) to develop new devices with better energy conversion performances and higher cost effectiveness. Our work is focused on modelling and verifying the development of a modified PV system, consisting of a normal PV panel coupled with a Phase Change Material (PCM). The system, proposed by several authors in scientific literature $[1,2]$, is based on the idea that decreasing the operating temperature of the panel causes an increase in its energy conversion efficiency.

A theoretical analysis was accomplished by writing the thermal balance of the system. To allow a better simulation of the thermal behaviour of the PV-PCM system, we have decided to develop two models based on different mathematical approaches; a lumped elements model and a finite difference model.

Furthermore, to validate the results coming from the two models we decided to realize an experimental set-up to start an on field monitoring of a PV-PCM system.

If the temperature of PV panel decreases, the exploitation of this simple technology could reduce $\mathrm{CO} 2$ emissions because the increasing of the energy conversion efficiency means more energy production and consequently less emissions of greenhouse gases respect the energy production by fossil fuel or normal PV panel.

\section{PHYSICAL MODEL}

The coupling of a PCM to a PV panel allows a limitation in temperature peaks on the rear part of the panel with a consequent increase in its energy conversion efficiency.

In the following figure the heat transfer process occurring in a PV/PCM system is schematized.

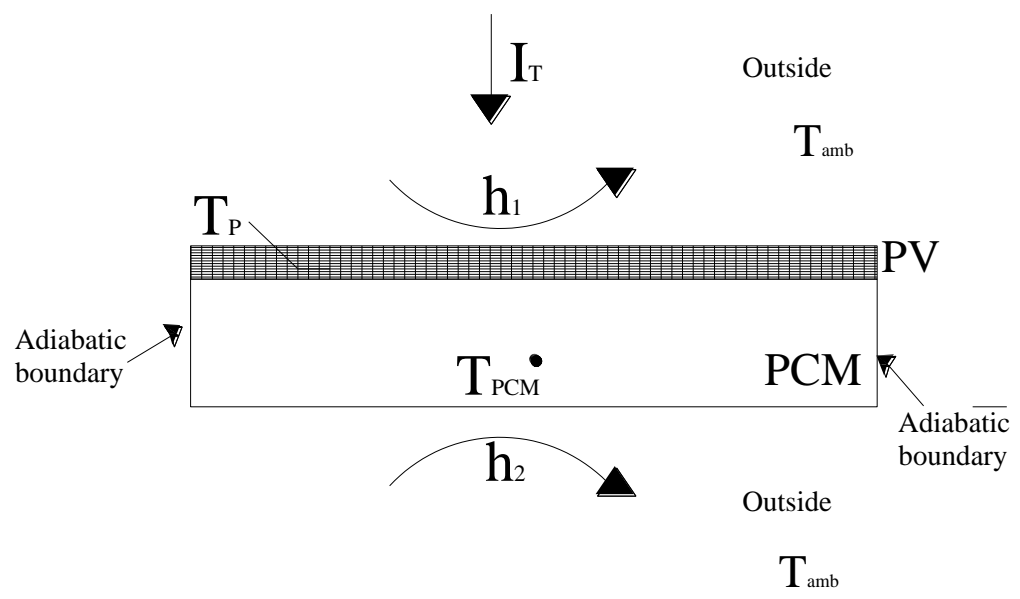

For simplicity's sake the thermal flux can be assumed mono-dimensional and orthogonal to the surface of the panel and we can take into consideration a pure PCM. Therefore the lateral surfaces of the system depicted in the above are considered adiabatic.

Photovoltaic technology is founded on the photovoltaic effect, which is based on the properties of certain semiconducting materials able to convert solar radiation into electric energy by an excitation of electrons from asymmetric impurity potentials.

When sun light enters the PV cell, a part of the energy of the photons is absorbed by the semiconductor's atoms, which release electrons from the negative layer of the cell. By 
flowing through an external circuit, these electrons reach the positive layer and produce electricity. The photovoltaic module or panel is the converter device which exploits the photovoltaic effect to produce electric energy.

The efficiency of a PV cell depends on:

- the kind of semiconductor material used (generally silicon);

- the intensity of the solar radiation;

- the operating temperature of the cell.

The power efficiency of PV is computed as its "peak power", which is the power that the PV module is able to generate in its maximum power point. The peak power of a PV cell is conventionally evaluated in the following "standard conditions": irradiation of 1000 $\mathrm{W} / \mathrm{m} 2$ and cell temperature of $25^{\circ} \mathrm{C}$.

The real power output of a solar PV module changes as a function of the direction of the sun, the solar insulation level and the ambient temperature. The typical power curve of a PV module has always a single maximum and, in the above defined standard conditions, only about $15 \%$ of the solar energy incident on a photovoltaic panel is converted into electricity; while the remaining part of the solar radiation is transformed into heat. The operating temperature is the most important factor to determine the energy conversion efficiency of a PV panel. In particular, the efficiency of a PV device is a decreasing function of the operating temperature. The work aims to develop an algorithm able to provide the change in temperature of a photovoltaic panel coupled with phase changing material.

\section{COMPUTATIONAL PROCEDURE}

The determination of the temperatures distribution has been addressed by using the lumped parameters method and the finite differences method. Concerning the finite differences method, the energy conservation equations for each nodal point have been defined. These equations have been developed for "Internal" nodes and for "Surface" nodes. To better address the changing phase in the case of internal nodes, the enthalpy conservation equations in the case of isothermal phase change were written. Finally, the finite difference equations were formulated with explicit scheme respect to the time variable. The comparison with analytical solutions available in some special cases allowed to verify the reliability and validity of the approach $[3,4]$.

\section{RESULTS \& DISCUSSION}

We are developing a lumped parameter model and finite difference model able to predict the thermal behaviour of a PV panel coupled with phase change material. The finite difference model was first tested with an analytical solution available for a simplified case and later was applied to a photovoltaic panel material phase change consists of paraffin. Data produced by the model are plausible and at the University of Palermo is running an experimental validation in open field.

\section{NOMENCLATURE}

$\mathrm{T}_{\mathrm{amb}}$ environmental temperature $[\mathrm{K}]$;

$\mathrm{T}_{\mathrm{PCM}} \mathrm{PCM}$ temperature $[\mathrm{K}]$;

IT solar radiation on the PV panel $\left[\mathrm{W} / \mathrm{m}^{2}\right]$;

$\mathrm{T}_{\mathrm{P}} \quad$ temperature of the panel (silicon temperature) $[\mathrm{K}]$;

$h_{1}, h_{2}$ convective heat transfer coefficients $\left[W /\left(m^{2} K\right)\right]$

\section{REFERENCES}

[1] M.J. Huang, P.C. Eames, and B. Norton Phase change materials for limiting temperature rise in building integrated photovoltaic Solar Energy. 80, 9 ,2006, 1121-1130

[2] M. J. Huang, P. C. Eames and B. Norton, Thermal regulation of building-integrated photovoltaic using phase change materials, International Journal of Heat and Mass Transfer 47, 2715-2733, 2004 
[3] E V.R. Voller and M. Cross, Accurate Solutions of Moving Boundary Problems Using Enthalpy Method. Int. J. Heat Mass Transfer 24 (1981).

[4] L. Rubestein, The Stefan Problem, Transactions in Mathematics Monograph No. 27. American Mathematical Society, 1971 


\section{Thermo-Chemical Material Models}

Households use a large amount of their energy consumption for space heating and domestic hot water. The energy consumption in the built environment can be reduced by energy saving measures (improved insulation, heat recovery, etc.). A substantial part of the remaining energy demand can be fulfilled by using renewable energy sources such as solar energy. During summer, the heat demand can be completely covered using solar heat, but in winter the heat demand exceeds the solar supply. To accommodate this lag between the solar energy surplus in summer and the energy demand in winter, a seasonal thermal storage is needed.

Traditionally, water is used for storing solar heat (for example, solar boiler) for short time periods. However, water-based long-term heat storage will require a large tank $\left(>50 \mathrm{~m}^{3}\right)$ that is often too large to be placed inside a building. As an alternative, it is possible to store energy by means of chemical processes, making use of the reversible reactions $C+$ heat $\Leftrightarrow A+B$.

In the charging mode during summer, solid $C$ dissociates under the influence of solar heat into components $A$ and $B$, which are stored separately. In the discharging mode during winter, the two components ( $A$ and $B$ ) react to form solid $C$ while releasing the stored solar heat. No reactions occur as long as the two components A and B are stored separately. Preliminary calculations show that sensible heat losses comprise approximately $10 \%$ of the total energy storage; this means that the remaining energy can be stored loss-free.

The Table below gives a list of candidate Thermo-Chemical Materials which can be used for long-term heat storage, see [1]. Dependent on their loading temperatures, energy densities, power densities and recyclability, TCM-materials can be used for (long-term) heat storage in the built environment and/or industry. To gain more insight into the heat and mass transfer processes taking place in these materials during charging and discharging, numerical modeling is needed ranging from the molecular- and micro-scale up to the macro- and reactor-scale. This insight can be used in a later stage to optimize specific properties of the storage materials with respect to their usage. The next chapters present an overview of the state-of-the-art modeling techniques on the various scales.

Candidate TCM-materials for long-term heat storage (from [1])

\begin{tabular}{|l|l|l|c|c|c|}
\hline $\mathrm{C}$ & $\mathrm{B}$ & $\mathrm{A}$ & $\mathrm{GJ} / \mathrm{m}^{3}$ & $\mathrm{~T} \rho \mathrm{C}$ ) & score \\
\hline $\mathrm{MgSO} 4 \cdot 7 \mathrm{H} 2 \mathrm{O}$ & $\mathrm{MgSO} 4$ & $7 \mathrm{H} 2 \mathrm{O}$ & 2.8 & 122 & $9.5 \%$ \\
\hline $\mathrm{SiO} 2$ & $\mathrm{Si}$ & $\mathrm{O} 2$ & 37.9 & 4065 & $9.0 \%$ \\
\hline $\mathrm{FeCO} 3$ & $\mathrm{FeO}$ (wustite) & $\mathrm{CO} 2$ & 2.6 & 180 & $6.3 \%$ \\
\hline $\mathrm{Fe}(\mathrm{OH}) 2$ & $\mathrm{FeO}$ & $\mathrm{H} 2 \mathrm{O}$ & 2.2 & 150 & $4.8 \%$ \\
\hline $\mathrm{CaSO} 4 \cdot 2 \mathrm{H} 2 \mathrm{O}$ & $\mathrm{CaSO} 4$ & $2 \mathrm{H} 2 \mathrm{O}$ & 1.4 & 89 & $4.3 \%$ \\
\hline $\mathrm{MgSO} 4 \cdot \mathrm{H} 2 \mathrm{O}$ & $\mathrm{MgSO} 4$ & $\mathrm{H} 2 \mathrm{O}$ & 1.3 & 216 & $2.7 \%$ \\
\hline $\mathrm{ZnCO} 3$ & $\mathrm{ZnO}$ & $\mathrm{CO} 2$ & 2.5 & 133 & $1.6 \%$ \\
\hline $\mathrm{CaCl} 2 \cdot 2 \mathrm{H} 2 \mathrm{O}$ & $\mathrm{CaCl} 2 \cdot 1 \mathrm{H} 2 \mathrm{O} 2 \mathrm{H} 2 \mathrm{O}$ & 0.6 & 174 & $1.1 \%$ \\
\hline $\mathrm{MgSO} 4 \cdot 7 \mathrm{H} 2 \mathrm{O}$ & $\mathrm{MgSO} 4 \cdot 1 \mathrm{H} 2 \mathrm{O}$ & $\mathrm{H} 2 \mathrm{O}$ & 2.3 & 105 & $1.1 \%$ \\
\hline
\end{tabular}

[1] Visscher, K., Veldhuis, J. B. J., Oonk, H. A. J., van Ekeren, P. J., and Blok, J.G., 2004, "Compacte Chemische Seizoenopslag Van Zonnewarmte; Eindrapportage," ECN Report No. ECN-C-04-074. 


\title{
AC1) MICRO-SCALE MODELLING
}

\author{
Atomistic simulations for heat transfer and chemical reactions on \\ micro/nano-scale \\ Silvia NEDEA \& Camilo RINDT, Eindhoven University of Technology, Eindhoven, The \\ Netherlands.
}

\section{INTRODUCTION}

Atomistic simulations are used to study heat transfer and chemical reactions both on nano and micro-scale. On nanoscale, molecular dynamics models are employed. With these, the dynamics of the chemical reactions on molecular levels are calculated, either using parameters that are determined in the models or that are derived from micro- or mesoscale experiments. Models on this level can help to understand the effect of impurities and crystal structure on the chemical parameters and thus the thermal energy storage potential of compact storage materials.

On micro scale, monte carlo models are used to describe the surface effects in micropores of salt-hydrates, a family of materials that have promising thermal energy storage capacities. The reaction kinetics parameters coming from molecular dynamics models are used together with the transport and diffusion mechanisms to determine the processes on micro scale. With the models, the effect of cracks in the grains of the material and the effect of nano structures on the surface can be determined. On the experimental side, new techniques have to be developed to give more direct experimental feedback to the numerical models. The experiments preferably would work on the scale of one grain of material or even on a smaller scale.

\section{THE PHYSICAL MODELS}

\section{Models for heat transfer}

Our model to study the molecular one-dimensional heat flow was developed for a micro/nano-channel consisting of two parallel plates of length $L_{y}$ at a distance $L_{x}$ apart from each other and of gas molecules confined between these two walls. Both plates have their own temperature, $T_{1}$ and $T_{2}$ respectively, where this temperature is uniform on the plate surface and constant in time. The gas consists of spherical particles of diameter a and mass $m$, at temperature $T$. The density of the gas can be expressed as $n$, being the number of particles per unit of volume, or using a reduced density $\eta$, which also takes the particle sizes into account and is related to the number density as $\eta=\pi \mathrm{na}^{3} / 6$ [2]. The mean free path of the gas particles is related to this reduced density. For a relatively dense gas with $\eta \approx 0.1$, the mean free path $\lambda\left(\lambda=1 /\left(\sqrt{ } 2 \pi a^{2} n Y(\eta)\right)\right)$ and the molecular diameter a have the same order of magnitude. The $Y(\eta)$ factor is the pair correlation function at contact $[1,2]$. The distance $L_{x}$ between the plates, in the $x-$ direction, is always such that both plates are only a few mean free paths apart.

For establishing a flow, the particles in the first $3 \lambda$ of the domain are accelerated such that every time step a particle in this region receives an extra velocity in the flow direction of $0.01 \Delta t$, where $\Delta t$ is the length of the time step. If a particle leaves the channel on the right side, it re-enters the channel on the left with a rescaled velocity according to a lower temperature. In this way the flow is cooled down $\left(T<T_{1}, T<T_{2}\right)$.

\section{Models for chemical reactions}

As the walls of these microchannels can have catalytic surface activity, and these reactions can be exothermic or endothermic, it is essential to couple these reactions with the heat properties of the system. For this the MD was improved by adding reactions to the system. The reactions are modelled using bonded interactions described by an harmonic potential. In catalytic reactions bonds are broken and new bonds are formed with the aid of catalysts till the equilibrium is reached. For the gas-surface interactions of 
a micro/nano-channel, firstly two molecules are apart from each other on the catalyst surface, then by surface diffusion they come close and a bond is formed and the resulting molecule diffuses back into the bulk. $\mathrm{CO}$ oxidation on silica and Pt was simulated using this stochastic MD approach [5] (see figure 1).
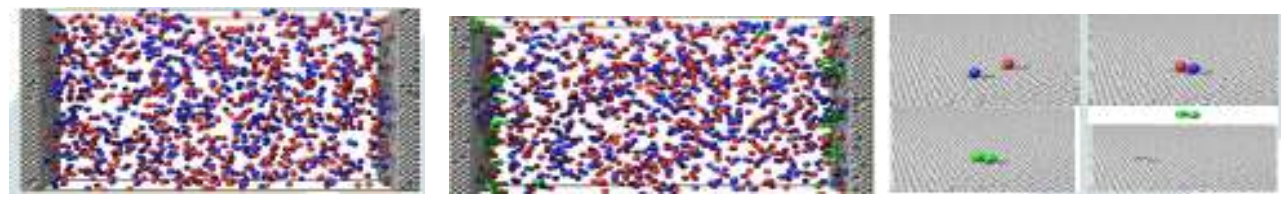

Figure 1: left : initial configuration for a $\mathrm{CO}$ oxidation system (CO-red, $\mathrm{O}-$ blue, $\mathrm{CO}_{2}-$ green) ; middle : configuration after some reactions ; right : surface reaction details.

\section{COMPUTATIONAL PROCEDURES}

Molecular Dynamics Methods for heat transfer and chemical reactions

\section{Heat Transfer}

In Molecular Dynamics, the Lennard Jones (LJ) potential is used to model the interactions between the gas-gas, gas-wall and wall-wall molecules $[4,5]$. These Lennard Jones potentials are especially appropriate for noble gases but it captures also the essence of all systems and can thus in principle be used for metals. Of course, more realistic potentials for metals are available taking into account many-atom interactions but because $L J$ captures the essence of all systems and we are not directly interested in one particular metal, this potential suffices for investigating the problem we are interested in of modelling hydrophilic and hydrophobic wall interactions and study the thermal behavior in the micro/nano-channel. The Lennard-Jones potential is given by the relation:

$$
V_{L J}=\varepsilon\left[\left(\frac{2 R_{v d w}}{r}\right)^{12}-2\left(\frac{2 R_{v d w}}{r}\right)^{6}\right]
$$

where $\varepsilon$ is the interaction strength and $R_{v d w}$ the van der Waals radius, a measure of the particle size. In order to simulate hard-sphere like interactions using MD, truncated shifted Lennard Jones (tsLJ) potentials were used for the interactions between gas molecules. This potential is defined as:

$$
V_{t s L J}=\left\{\begin{array}{lll}
V_{L J}(r)-V_{L J}\left(r_{c}\right) & \text { if } & r \leq r_{c} \\
0 & \text { if } & r>r_{c}
\end{array}\right.
$$

with rc is the cut-off radius. This tsL $\mathrm{J}$ is used to keep only the repulsive contribution as a model for hard sphere molecules. The walls are kept together by a relatively strong interaction strength $\varepsilon=6.0$ in the $L$ J potential. The gas-wall interactions can be hydrophilic (attractive) or hydrophobic (repulsive) wall interactions. Attractive wall interactions are modelled by $L J$ with $\varepsilon$ between 0.10 and 0.5 , and repulsive wall interactions by tsLJ with $\varepsilon=1.0$. A figure of the potentials used in the simulations is given in figure 2.

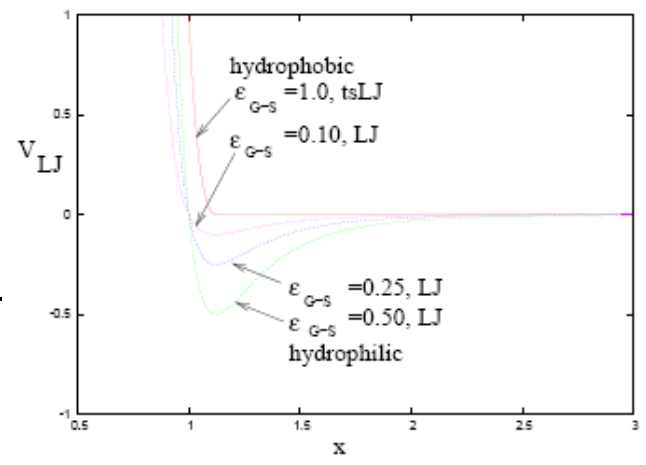

Figure. 2: Hydrophilic wall interactions by Lennard Jones potential with $\varepsilon=0.10,0.20$,

4 - Compact Thermal Energy Storage 
0.50 and hydrophobic wall interactions modelled by truncated shifted Lennard Jones with $\varepsilon=1.0$

From the MD simulations, macroscopic properties can be derived, such as the density, the mean velocity, the temperature, the heat flux, and the stress. The heat flux vector $\vec{q}$ is given by the relation:

$$
\vec{q}=\frac{d}{d t} \sum_{i} \vec{r}_{i} E_{i}
$$

with $\vec{r}_{i}$ the position and $E_{i}$ the energy associated with particle $\mathrm{i}$. This can be split again into a kinetic and a potential part:

$$
\begin{aligned}
& \vec{q}_{k i n}=\sum_{i} E_{i}^{k i n} \vec{v}_{i}=\frac{1}{2} \sum_{i} m_{i} v_{i}^{2} \vec{v}_{i} \\
& \vec{q}_{p o t}=\frac{1}{2} \sum_{i, j}\left(\vec{F}_{i j} * \vec{v}_{i}\right) \vec{r}_{i j}+\sum_{i} E_{i}^{p o t} \vec{v}_{i}
\end{aligned}
$$

where $m_{i}$ and $\vec{v}_{i}$ are, respectively, the mass and the velocity of particle $\mathrm{i}$, and $\vec{F}_{i j}$ and $\vec{r}_{i j}$ the interaction force and separation vector between particle $\mathrm{i}$ and $\mathrm{j}$.

\section{Chemical reactions}

The first option is to use stochastic reactions in the MD simulations. The reactions are interleaved with the MD steps and are implemented as stochastic processes having given probabilities. The probability of a particle $i$ to be involved in a certain reaction of type $x$ is given by the probability $\mathrm{p}_{\mathrm{x}}^{\mathrm{i}}$. In order to model the role of catalysis as well, this probability has been split in two parts:

$$
p_{x}^{i}=a_{x}+b_{x} \sum_{j=c a t} f\left(r_{i j}\right)
$$

where $f(r)=1-r / d$, if $r \leq d$, and zero otherwise. The first term represent the probability of a particle to be involved in an autonomous reaction. The second contribution increases this probability in the case of the presence of catalysts in the particles vicinity. Every catalyst particle $j$ with radius $d$ increases the reaction probability of particle $i$ by an amount depending on their mutual distance. This probability will be much smaller than one because the chance that the reaction takes place within the short time interval of one iteration is small.

To obtain all these probabilities more accurate atomistic models for the reactions should be applied. Our goal is to parameterize these potentials using reactive force fields ReaxFF [6]. ReaxFF is a bond-order force field method that includes a geometry-dependent polarizable charge distribution, allowing reactive, atomistic scale dynamic simulations at computational expense magnitudes lower than quantum mechanical (QM) simulations. This empirical potential is highly transferable allowing description of covalent, metallic, ionic and mixed systems across periodic system. ReaxfF system energy description includes 2-body, 3-body, 4-body, and multibody contribution. The advantages of using this forcefield is: a) the force field has no discontinuities in energy or forces even during reactions; $b$ ) it is not needed to predefine reactive sites or reaction path ways (potential functions should be able to automatically handle coordination changes associated with reactions); c) each element is represented by only one atom type in the force field (the 
force field should be able to determine equilibrium bond lengths, valence angles, etc. from chemical environment).

\section{Monte Carlo Methods for heat transfer and chemical reactions}

\section{Heat transfer}

The method used is an extended version of the directed simulation Monte Carlo method. The method is based on the Enskog kinetic equation. This Enskog equation is an extension of the Boltzmann equation to dense fluids and has the form:

$$
\frac{\partial F}{\partial t}+\xi \cdot \nabla F=J_{E}(F, F)
$$

where $F(x, \xi, t)$ is the one-particle distribution function of the molecular velocities $\xi$. The collision integral $J_{E}(F, F)$ keeps the same binary structure of the corresponding Boltzmann term. This equation can be solved numerically by means of a particle simulation method to study the one-dimensional steady heat flow in a dense hard-sphere gas. In this particle simulation method the molecules are represented by mathematical particles, which we consider having the same size as the particles of the physical model. Each particle is characterized by its position and velocity. Particles are advected with their velocities and then they collide stochastically. During the collision steps collision partners are selected from prescribed collision probabilities $[1,2,3]$.

\section{Chemical reactions}

Monte Carlo models are used to describe the surface effects in micropores, nucleation and growth processes for salt-hydrates. The reaction kinetics and diffusion parameters coming from MD are used to parameterize MC and to determine the effect of cracks in the grains of the material and the effect of nano structures on the surface. The MC Stochastic model for nucleation and growth are described in $[7,8]$ and an example is presented in figure 3 .

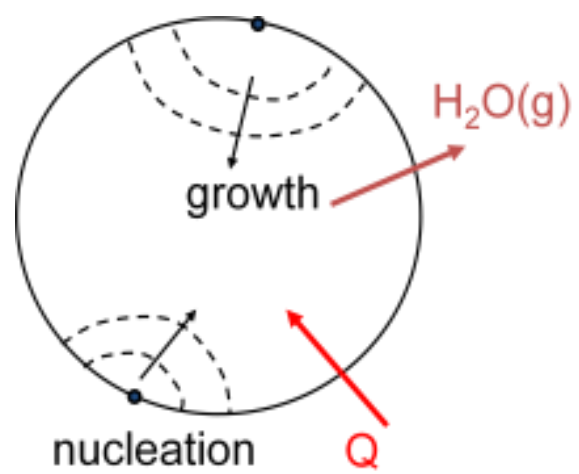

Figure 3: Schematic of nucleation and growth in a grain during the dehydration process.

Dehydration starts with nucleation on the surface followed by inwards growth. Nucleation and growth are described by stochastic processes with specified rates on grain and powder level. Both nucleation and growth can be a function of temperature and pressure. The input parameters, growing rate, nucleation rate, grain size, and volume are fitted to match realistic values.

\section{RESULTS AND DISCUSSIONS}

Application A: micro/nano-channel cooling

The above described methods are extended in order to be able to analyse heat transfer in micro/nano-channels in different flow regimes, and to more accurately simulate the solid- 
gas interface. A flow is imposed by applying an extra force on particles situated in the first $3 \lambda$ of the channel. Different MC and MD models can be considered for more accurate gas-surface interactions. In the MD model, the interactions between molecules can be pure repulsive (PR) or attractive repulsive (RA) [4], while in MC different boundary conditions can be imposed (thermal wall, reflective, periodic, etc.).

When thermal wall boundary conditions were used in the no-flow regime, pure MD and pure $M C$ results corresponded very well in the bulk, deviations appearing only in the immediate vicinity of the wall. When the walls are explicitly introduced in the simulations, the discrepancies appear even between different pure MD simulations where walls are either attractive (hydrophilic-RA interactions) or repulsive (hydrophobic-PR interactions).

In Figure 4, for a cold flow imposed between two warm walls of a channel $\left(T=0.9 T_{0}, T_{1}=\right.$ $\mathrm{T}_{2}=1.0 \mathrm{~T}_{0}$ ) we see that different model interactions influence the properties in the channel. The physically more realistic RA model predicts more heat transfer than the more simplified PR model. The flow velocity is higher for hydrophobic interactions than for hydrophilic ones (see figure 5). The attraction causes hardly any slip while the repulsion causes a large slip near the wall and this results in a higher temperature of the gas in case of the attractive than in case of the repulsive. Thus, although the flow rate is smaller, looking at the temperature profiles we see that the amount of heat that can be removed is larger in case of attractive walls because of the better heat transfer over the interface. This shows once again, that the accuracy of the simulation results depends on how accurate we model the interactions between gas and wall molecules and that pure $M C$ is not good enough to describe these effects.

We conclude that we can dissipate more heat not only by increasing flow velocity, but also by increasing the gas-surface interactions.
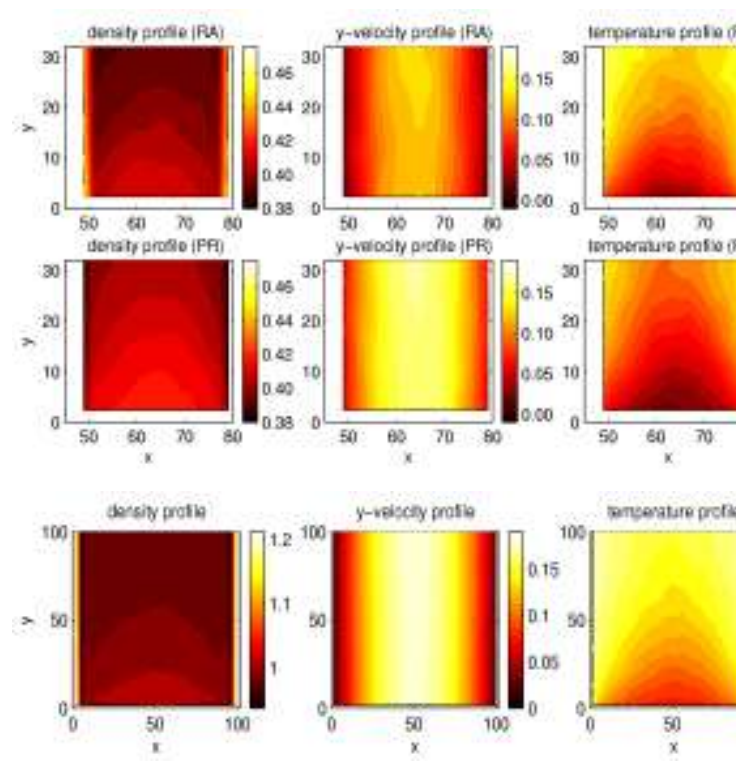

Figure 4. Density, flow velocity and temperature distributions in the channels for different sets of interaction parameters, for a cold flow imposed between the two vertical warm walls of the channels: a) $M D-R A$ (repulsive and attractive) interaction between gas and wall particles, b) $M D-P R$ (purely repulsive) interaction between gas and wall particles, c) MCthermal wall boundary conditions. 


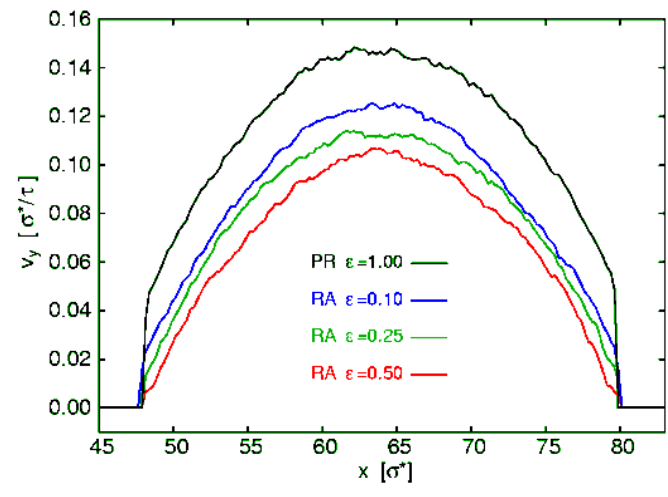

Figure 5. Flow velocity for purely repulsive $(P R)$ and repulsive-attractive $(R A)$ gas-wall interaction. Higher velocity profile in case of $P R$ interactions than in case of $R A$ interactions.

\section{Application B: heat storage systems}

ReaxFF is used to study hydration and dehydration of $\mathrm{MgSO}_{4}$. The ReaxFF parameters for both $\mathrm{Mg}$ and sulphates are available and they should be tested for $\mathrm{MgSO}_{4}$-reactions. QMdata on $\mathrm{MgSO}_{4}$ crystal equations of state and heats of formation are needed for these simulations and also QM-data related to the barriers and reaction energy related to the hydration/dehydration reactions. The sulphate ReaxFF description has already been tested for $\mathrm{H}_{2} \mathrm{SO}_{4}$-proton transfer reactions and it is working for this kind of systems.

The hydration process was simulated using ReaxFF considering a water droplet $\left(52 \mathrm{H}_{2} \mathrm{O}\right.$ molecules), and an amorphous $\mathrm{MgSO}_{4}$ (25 molecules) at $\mathrm{T}=300 \mathrm{~K}$. The exothermic solvation process was simulated for 100000 steps. From the last configuration on this process, the dehydration was started by heating up the crystal from $300 \mathrm{~K}$ to $800 \mathrm{~K}$, in another 100000 steps. This results in the evaporation of (most) of the water, while the $\mathrm{MgSO}_{4}$ particle does not evaporate.

Preliminary results of the simulations show that:

- Simulations needed for longer times and bigger systems. The force field was trained against a good amount of QM-data, including $\mathrm{H}_{2} \mathrm{SO}_{4} / \mathrm{H}_{2} \mathrm{O}$ bonding, $\mathrm{Mg}$ solvation and $\mathrm{Mg}, \mathrm{MgO}, \mathrm{Mg}\left(\mathrm{OH}_{2}\right)$ bulk phases.

- Additional training for the $\mathrm{MgSO}_{4}$ /water interactions might be useful.

- Using longer and larger simulations (using, possibly, parallel ReaxFF) we could study the water adsorption/desorption cycles of $\mathrm{MgSO}_{4}$ and see how the energy signal changes.

- From preliminary results: no reactive events (no water dissociation visible); this might be correct, but we should check the energetics for water dissociation against QM.

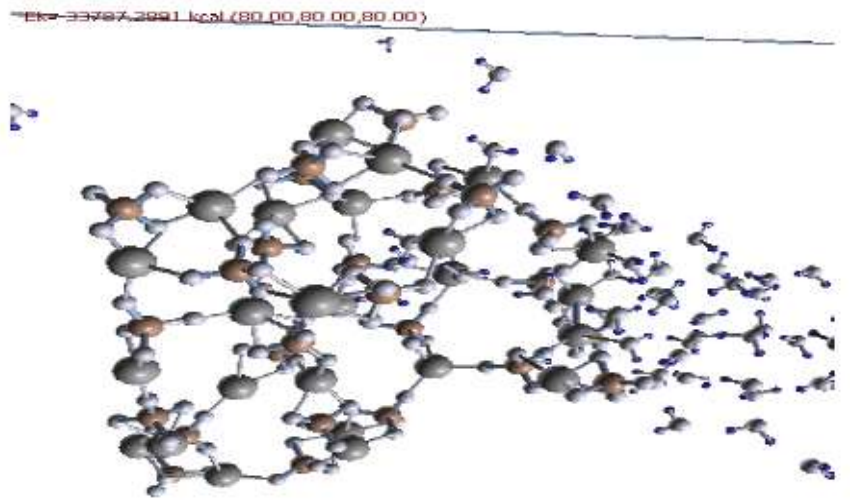

sersoo steps
Fig. 6 The initial molecular configuration for the hydration process of MgSO4 on molecular level consisting of 52 H2O molecules an amorphous MgSO4 (25 molecules) at $T=300 \mathrm{~K}$. 


\section{NOMENCLATURE}

a molecular diameter

$\Delta \mathrm{t} \quad$ time step

$E_{i} \quad$ energy of particle $i$

$\varepsilon \quad$ interaction strength in the $L$ potential

$\eta \quad$ reduced density

$\mathrm{F}$ particle distribution function

$\vec{F}_{i j} \quad$ interaction force between particle $\mathrm{i}$ and $\mathrm{j}$

$J_{E} \quad$ collision integral

LJ Lennard Jones potential

$L_{x} \quad$ distance between the parallel walls

$L_{y} \quad$ length of the parallel walls

$\lambda$ mean free path

$\mathrm{m}_{\mathrm{i}} \quad$ mass of particle $\mathrm{i}$

MC Monte Carlo

MD Molecular Dynamics

n number density

$p_{x}^{i} \quad$ probability of particle $\mathrm{i}$ and reaction $\mathrm{x}$

$\mathrm{q}_{\mathrm{x}}$ heat flux

$\vec{q} \quad$ heat flux vector

$r_{c} \quad$ cut-off radius

$\vec{r}_{i} \quad$ position vector of particle $\mathrm{i}$

$\vec{r}_{i j} \quad$ separation vector between particle $\mathrm{i}$ and $\mathrm{j}$

$\mathrm{R}_{\mathrm{vdw}}$ van der Waals radius

tsLJ truncated shifted Lennard Jones potential

$T$ temperature

$\vec{v}_{i} \quad$ velocity of particle i

$Y \quad$ pair correlation function

\section{BIBLIOGRAPHY}

[1] A.Frezzotti. A particle scheme for the numerical solution of the Enskog equation. Phys.Fluids, 9(5):1329-1335, 1997.

[2] A.Frezzotti. Monte Carlo simulation of the heat flow in a dense hard sphere gas. J.Mech.B/Fluids, 18:103-119, 1999.

[3] S.V.Nedea, A.J.Markvoort, A.J.H.Frijns, A.A.van Steenhoven, P.A.J.Hilbers. Hybrid method coupling molecular dynamics and Monte Carlo simulations to study the properties of gases in micro and nanochannels, Phys. Rev.E, 72, 016705, 2005.

[4] A.J.Markvoort, P.A.J.Hilbers, S.V.Nedea. Molecular dynamics study of the influence of wall-gas interactions on heat flow in nanochannels, Phys.Rev.E, 71, 066702, 2005.

[5] A.J.Markvoort. Towards Hybrid Molecular Dynamics. PhD thesis, 2006, Technical University Eindhoven. ISBN:90-386-3037-9.

[6] A.C. van Duin, A.Strachan, S.Stewman, Q.Zhang, X.Xu, W.A.Goddard. ReaxFF for Silicon and Silicon Oxide Systems. J. Phys. Chem. A, 2003, 107(19), 3803-3811.

[7] C.Helbert, E.Touboul, S.Perrin, L.Carraro, M.Pijolat. Stochastic and deterministic models for nucleation and growth in non isothermal or (and) non isobaric powder transformations Chemical Engineering Science, 2004, 59(7), 1393-1401.

[8] L.Favergeon, M.Pijolat, C.Helbert, Phys. Chem. Chem. Phys. 7, 3723, 2005. 


\section{Hybrid Molecular Dynamics - Monte Carlo simulations for the flow in a micro-channel}

Silvia NEDEA \& Camilo RINDT, Eindhoven University of Technology, Eindhoven, The Netherlands.

\section{INTRODUCTION}

Thermochemical heat storage is the storage of heat using the endothermic reactions of chemical compounds. During the inverse exothermic reaction, the stored thermal energy is released again, generally at a different temperature level. On nanoscale, molecular dynamics models are employed. With these, the dynamics of the chemical reactions on molecular level is calculated, either using parameters that are determined in the models or that are derived from micro- or mesoscale experiments. Models on this level can help to understand the effect of impurities and crystal structure on the chemical parameters and thus the thermal energy storage potential of compact storage materials.

On micro scale, monte carlo models are used to describe the surface effects in micropores of thermochemical materials. The reaction kinetics parameters coming from molecular dynamics models are used together with the transport and diffusion mechanisms to determine the processes on microscale. With the models, the effect of cracks in the grains of the thermomechanical material and the effect of nano structures on the surface can be determined.

Our research focuses on the development of a hybrid Molecular Dynamics - Monte Carlo simulation tool for the dynamical behaviour of water molecules in the interlayer and on the surface structure of heat storage materials over a range of temperatures. A hybrid simulation method [4] coupling Molecular Dynamics and Monte Carlo simulation was developed and it was primarily used to study the gas-surface interactions for a gas/liquid in contact with a solid wall. The method was applied to study the flow properties in micro/nano-channels. We first introduce the physical model, then we explain the coupling in the hybrid MD-MC method. Simulation results are validated by comparison with pure MD simulation results of a system consisting of dense gas molecules confined between the walls of a micro/nano-channel.

\section{THE PHYSICAL MODEL}

Model for the flow

The model to study the molecular fluid flow was developed for a micro/nano-channel consisting of two parallel plates of length $L_{y}$ at a distance $L_{x}$ apart from each other and of gas molecules confined between these two walls. Both plates have equal temperature. The gas consists of spherical particles of diameter a and mass $m$, at temperature $T$. The density of the gas can be expressed as $n$, being the number of particles per unit of volume, or using a reduced density $\eta$, which also takes the particle sizes into account and is related to the number density as $\eta=\pi \mathrm{na}^{3} / 6$ [2]. The mean free path of the gas particles is related to this reduced density. For a relatively dense gas with $\eta \approx 0.1$, the mean free path $\lambda\left(\lambda=1 /\left(\sqrt{ } 2 \pi a^{2} n Y(\eta)\right)\right)$ and the molecular diameter a have the same order of magnitude. The $Y(\eta)$ factor is the pair correlation function at contact $[1,2]$. The distance $L_{x}$ between the plates, in the $x$-direction, is always such that both plates are only a few mean free paths apart.

For establishing a flow, the particles in the first $3 \lambda$ of the domain are accelerated such that every time step a particle in this region receives an extra velocity in the flow direction of $0.01 \Delta t$, where $\Delta t$ is the length of the time step. If a particle leaves the channel on the right side, it re-enters the channel on the left.

\section{Hybrid Molecular Dynamics - Monte Carlo Method}

In order to perform more efficient simulations, we propose a simulation method that combines the advantages of the Molecular Dynamics and Monte Carlo simulations. 
How this is done is shown schematically in figure 1 for the case where MD is used in the left half of the simulation domain (regions I and II) and MC in the right half (regions III and IV). Our simulation algorithm consists of the following steps:

1. First an initial configuration for the whole system is created. The positions of the particles are randomly generated in the simulation domain, and the velocities of the particles are generated from a Maxwell-Boltzmann distribution.

2. The particles in the region in which MD is performed are send to the MD simulator and analogously the particles in the $M C$ range are send to the $M C$ simulator.

3. However, the MD simulation needs information from the neighboring $M C$ particles and vice versa. This is obtained by creating an interface coupling the two subdomains. The MD simulation is extended with a buffer layer $\left(B L_{M D}\right)$ to which the information of the MC particles in region III are copied and analogously the MC simulation is extended with a buffer layer $\left(B L_{M C}\right)$ to which the information of the MD particles in region II are copied.

4. Now both the MD and the MC simulator can run in parallel. This implies that the MC simulator performs one iteration, updating the positions and velocities of all its particles. Parallel to this, the MD simulator should simulate the same time interval. Because the time step size that can be made in one MD iteration is usually small compared to the time step size in MC, we have to do a number of MD time steps for every single MC simulation step.

5. The information for the whole system is now obtained by recombining regions I and II from MD with regions III and IV from MC. And the simulation can be continued with a new iteration of the hybrid procedure by restarting from step 3.

The first important point is about updating the buffer layers after each iteration of the hybrid method. A straightforward approach is to provide the buffer layers $B L_{M D}$ and $B L_{M C}$ with a new copy of regions III and II respectively. In [3], we have previously investigated the coupling between the two methods in this way which was realized by importing and exporting particles from one simulator to the other. However, as we couple two simulation methods based on a different mechanism of computing the interactions between particles, problems are encountered as expected when trying to couple the less detailed method with the more accurate method. This is the case for coupling the MC and MD particle domains.

Whereas for MD to MC particle coupling, particles from the MD domain can be imported directly into the MC domain using the exact positions and velocities, this cannot be done for MC to MD particle coupling as in MC simulations particles can overlap each other. Imported into the MD domain, this would result in very large forces, leading to a high temperature jump in the interface layer caused by energy conservation problems. An option is to reposition the overlapping particles. A new random position is chosen which is accepted or rejected according to a probability distribution depending on the potential energy of the particle at that new position. However, because this has to be done every iteration an equilibrium MD configuration is never formed.

Here an alternative method is used for the MC to MD coupling, where macroscopic properties are copied instead of single particles. In this method the positions and velocities of the particles in the MD buffer layer $\mathrm{BL}_{\mathrm{MD}}$ are kept and subsequently scaled to match the macroscopic quantities from MC region III.

Our hybrid simulator consists of three components, the MD component for the MD simulations, the $\mathrm{MC}$ component for the MC simulations, and an interface component between the first two components, coupling the MD and MC simulations. The MD and MC components are independent, the MD and MC steps being computed by two different independent codes based on an already developed software [7] which were implemented in different programming environments, MC simulator in Fortran77, and the MD one in C. Being independent, the MD and MC components can reside on different computers, and can run in parallel being synchronized and coupled by an interface written in Python. 


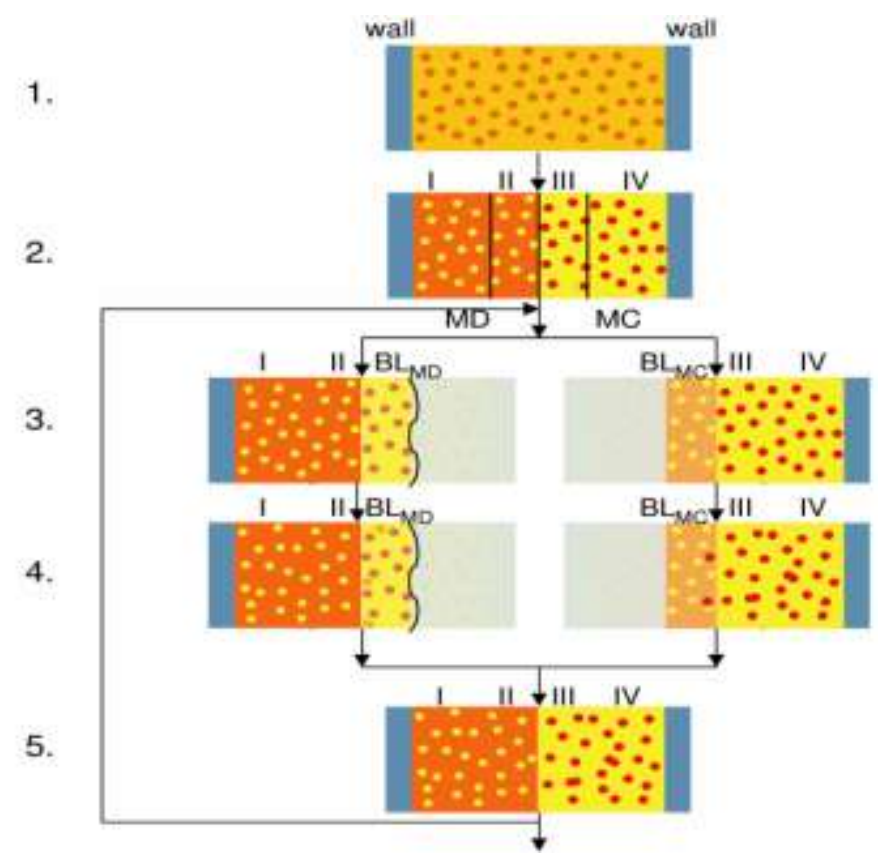

Figure 1: The coupling of the MD and MC simulations is obtained via an interface layer. The curved-line boundary of the $M D$ boundary layer $B L_{M D}$ corresponds to the soft (movable) border.

\section{RESULT AND DISCUSSION}

To be able to compare the hybrid simulations with MC and MD for complex boundary conditions, we considered the simple hard-sphere model for the molecules both in MD and in $M C$, for a flow without heat transfer [6]. When we compare the flow for hardsphere, we notice again that MC is different from MD in the middle of the channel even for very high epsilon. When going to lower densities, the relative differences decrease (see figure $2 \mathrm{a}$ and $2 \mathrm{~b}$ ). We expect at lower density, they will better correspond. This is caused by the fact that even for the hard-sphere model at high densities differences appear between the MD and MC densities next to the wall [4,5]. The MC peaks are smaller than the MD ones in the oscillation region, and this causes less collisions in MC (less energy transferred between the molecules next to the wall boundary).
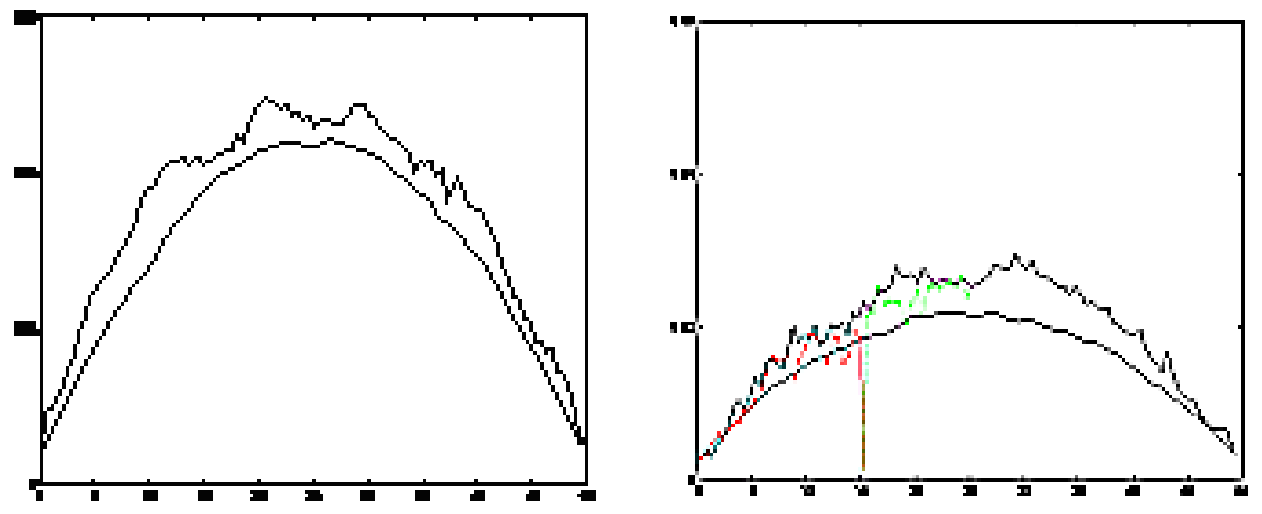

Figure 2: Comparison of the axial velocity between MC, MD and hybrid simulations for different densities: a) MD-thermal wall and MC-thermal wall for a fully developed flow profile for $\eta=0.1$ (low line-MC, high line-MD), b) MD-thermal wall, MC-thermal wall (low line-MC, high line-MD) and hybrid-thermal wall for the left side of the channel when $15 \% M D-85 \% M C$, for $\eta=0.2$. 
Hybrid method would thus help to overcome this problem, by simulating collisions using MD near the wall and $M C$ in the middle. In this way the MC molecules could be thermalized properly (MD-like) by the wall. In figure $2 b$, looking at the hybrid velocity profile for a fully developed flow when the simulation domain was splitted in 15\%MD and $85 \% \mathrm{MC}$, we notice that this profile has the same slip near the boundaries as the MD and also the same maximum velocity. In the future, coupling more complex MD models with MC near the boundary of the wall is going to be investigated.

\section{NOMENCLATURE}

a molecular diameter

$\mathrm{BL}$ buffer layer

$\Delta \mathrm{t} \quad$ time step

$\eta \quad$ reduced density

$\lambda$ mean free path

$L_{x} \quad$ distance between the parallel walls

$L_{y} \quad$ length of the parallel walls

$\mathrm{m}$ molecular mass

MC Monte Carlo

MD Molecular Dynamics

n number density

$T$ temperature

$\mathrm{Y}$ pair correlation function

\section{BIBLIOGRAPHY}

[1] A.Frezzotti. A particle scheme for the numerical solution of the Enskog equation. Phys.Fluids, 9(5):1329-1335, 1997.

[2] A.Frezzotti. Monte Carlo simulation of the heat flow in a dense hard sphere gas. J.Mech.B/Fluids, 18:103-119, 1999.

[3] A.J.H.Frijns, S.V.Nedea, A.J.Markvoort, A.A.van Steenhoven, P.A.J.Hilbers. Molecular Dynamics and Monte Carlo Simulations for Heat Transfer in Micro/Nanochannels, Int.J.Multiscale Comp.Eng., in press, 2006.

[4] S.V.Nedea, A.J.Markvoort, A.J.H.Frijns, A.A.van Steenhoven, P.A.J.Hilbers. Hybrid method coupling molecular dynamics and Monte Carlo simulations to study the properties of gases in micro and nanochannels, Phys. Rev.E, 72, 016705, 2005.

[5] S.V.Nedea, A.J.H.Frijns, A.J.Markvoort, A.A.van Steenhoven, P.A.J.Hilbers, Deviations of the results for the properties of a dense hard-sphere gas near the walls of a microchannel using the hybrid Molecular Dynamics-Monte Carlo simulation method, ICMM03, ASME, Toronto, Canada, CD, 2005.

[6] S.V.Nedea, A.J.H.Frijns, A.A.van Steenhoven, A.P.J.Jansen, Properties of a dense hard-sphere gas near the walls of a microchannel, ICMM02, ASME, Rochester US, 289-296, 2004.

[7] K.Esselink, P.A.J.Hilbers. Efficient parallel implementation of molecular dynamics on a toroidal network. J.C. Phys., 106:108-114, 1993. 


\section{AC3) MACRO-SCALE MODELLING}

\section{Macro-scale modelling of adsorption processes}

Henner KERSKES \& Barbara METTE \& Sebastian ASENBECK, Institute for Thermodynamic and Thermal Engineering (ITW), University of Stuttgart, Germany

\section{INTRODUCTION}

At ITW currently three projects are dealing with thermochemical heat storage in different fields and development stages, accompanied by numerical investigations respectively:

- MONOSORP(2005-2007): an open adsorption store filled with "monolithes" (zeolites extruded in honey comb structures) has been built up in labscale during the period of Task32; a 1-D numerical model has been used to describe heat- and mass-transfer within the store. The system of PDE is solved by PDEX (a 1-D parabolic PDE-solver developed at University of Stuttgart with the Conrad-Zuse Zentrum, Berlin $/ 1,2 /$ ) and finally coupled to a complete long term system simulation (TRNSYS). During the design process the software package FLUENT has been used to carry out flow simulations for optimizing geometry and shape of the store.

Currently the labscale system is in operation to collect further data, especially concerning the solar desorption cycle.

- KOWAS (2008-2011): a small zeolite store shall be combined with a water store, mainly to improve solar energy fraction of a domestic solar hot water system during summer; numerical simulations with FLUENT and long term system simulations with TRNSYS are planned.

- CWS (2008-2011): a chemical heat store in labscale shall be developed and built up in order to demonstrate the feasibility of a reversible gas-solid reaction for highly efficient and/or long term heat storage applications; detailed numerical investigations are planned by the use of the software package COMSOL/Multiphysics. Current activities include building up a 2-D model describing heat- and mass transfer as well as the pressure/velocity distribution in a packed bed reactor. In combination with experimental investigations these simulations are meant to gain a deeper understanding of the interdependcies of reaction, heat- and mass-transfer inside the packed bed and shall support the design process of the labscale reactor.

Additionally, long term simulations of the complete system are planned to do in TRNSYS. Therefore, the 1D-solver PDEX, used for the numerical description of the sorption process in the MONOSORP project, has recently been implemented in a TRNSYS-Type.

The following sections are all subdivided into two parts, one concerning the numerical work which has been done in the Monosorp project and a second part concerning simulations which are planned within the CWS project.

\section{PHYSICAL MODEL}

While the Monosorp model considers dynamic behaviour in only one (axial) dimension, a second extended model is set up to consider additionally the radial dimension and the equations of motion; however, now dealing with packed beds instead of flow channels, the originally seperated heat balance equations for gaseous and solid phase are merged resulting into a so called "quasi-homogenous model".

MONOSORP: In the Monosorp-project a heterogenous 1-D two-phase model has been used to model the sorption processes within the zeolite channels. The system of parabolic PDE consists of a heat- and mass balance equation for the solid (zeolite) and gaseous phase (moist air) respectively; additionally, an algebraic equation (5) is set up for the calculation of the adsorption equillibrium: 
Heat balance (gaseous phase):

$$
\varepsilon \rho_{g} c_{p, g} \frac{\partial \vartheta_{g}}{\partial t}=-G_{z} c_{p, g} \frac{\partial \vartheta_{g}}{\partial z}+\varepsilon \lambda_{e f f} \frac{\partial^{2} \vartheta_{g}}{\partial z^{2}}+\alpha_{s, g}(z) a_{v}\left(\vartheta_{s}-\vartheta_{g}\right)
$$

Heat balance (solid phase):

$$
(1-\varepsilon) \rho_{s} c_{p s} \frac{\partial v_{s}}{\partial t}=(1-\varepsilon) \lambda_{s} \frac{\partial^{2} \vartheta_{s}}{\partial z^{2}}+\frac{\dot{m}_{a d s}}{V} \cdot \Delta h_{a d s}-\alpha_{s g}(z) a_{v}\left(\vartheta_{s}-\vartheta_{g}\right)
$$

Mass balance (water vapour within gaseous phase):

$$
\varepsilon \rho_{g} \frac{\partial w_{H_{2} O_{g}}}{\partial t}=-G_{z} \frac{\partial w_{H_{2} O_{g}}}{\partial z}+\varepsilon D_{e f f} \frac{\partial^{2} w_{H_{2} O_{g}}}{\partial z^{2}}-\frac{\dot{m}_{a d s}}{V}
$$

Mass balance (water vapour within solid phase):

$$
(1-\varepsilon) \rho_{s} \frac{\partial w_{H_{2} O} O_{s}}{\partial t}=\frac{\dot{m}_{a d s}}{V}
$$

Adsorption equillibrium:

$$
0=X_{G G H_{2} O}-X_{i s o}
$$

A Langmuir approach is used to describe the adsorption isotherms:

$$
\mathrm{X}_{\text {iso }}=\mathrm{X}_{\text {iso }}\left(\vartheta_{\mathrm{g}}, \mathrm{w}_{\mathrm{H} 2 \mathrm{O}, \mathrm{g}}\right)
$$

With the surface to volume ratio $\mathrm{a}_{\mathrm{v}}:=\frac{\mathrm{O}_{\mathrm{s}}}{\mathrm{V}}=(1-\varepsilon) \frac{\mathrm{O}_{\mathrm{s}}}{\mathrm{V}_{\mathrm{s}}}$ and the water load fraction of the solid phase $\mathrm{X}_{\mathrm{s}}:=\frac{m_{\mathrm{H} 2 \mathrm{O}, \mathrm{s}}}{m_{s, 0}}=\frac{\mathrm{w}_{\mathrm{H} 2 \mathrm{O}, \mathrm{s}}}{1-\mathrm{w}_{\mathrm{H} 2 \mathrm{O}, \mathrm{s}}}$, the adsorbed water vapour mass flow is calculated by:

$$
\frac{\dot{\mathrm{m}}_{\mathrm{ads}}}{\mathrm{V}}=\frac{\rho_{\mathrm{s}, 0} \cdot \beta_{\mathrm{H} 2 \mathrm{O}}(\mathrm{z}) \cdot \mathrm{a}_{\mathrm{v}} \cdot\left(X_{\mathrm{GG}, \mathrm{H} 2 \mathrm{O}}-X_{s}\right)}{1+\varsigma}
$$

The mass transfer coefficient $\beta_{\mathrm{H} 2 \mathrm{O}}$ considers the transport of water vapour within the gaseous phase to the zeolite walls. Water molecule diffusion within the solid phase tends to be a limiting factor with proceeding water uptake (cmp. "shrinking core approach") and therefore is taken into account by an additional inhibitor term $\zeta=\zeta\left(\mathrm{w}_{\mathrm{H} 2 \mathrm{O}, \mathrm{s}}\right)$. Experiments have been carried out to identify the corresponding parameters for the given zeolite structure. Both heat and mass transfer coefficiants $\alpha_{s, g}(z)$ and $\beta_{\mathrm{H} 2 \mathrm{O}}(z)$ are locally calculated using empirical correlations.

The numerical model has originally been developed for a different field of research, where it has been well validated and is widely used, see $/ 3,4 /$.

Nomenclature Monosorp:

\begin{tabular}{|lll}
\hline$a_{v}$ & {$\left[\mathrm{~m}^{2} / \mathrm{m}^{3}\right]$} & solid particle surface area per store volume \\
$c_{p}$ & {$[\mathrm{~J} /(\mathrm{kg} \mathrm{K})]$} & specific heat capacity \\
$D_{\text {eff }}$ & {$\left[\mathrm{m}^{2} / \mathrm{s}\right]$} & effective mass dispersion coefficient \\
$G_{z}$ & {$\left[\mathrm{~kg} /\left(\mathrm{s} \mathrm{m}^{2}\right)\right]$} & mass flow per store cross area \\
$\Delta h_{a d s}$ & []$\left./ \mathrm{kg}_{\text {vap }}\right]$ & adsorption enthalpy \\
$\dot{m}_{a d s}$ & {$\left[\mathrm{~kg} g_{\text {vap }} / \mathrm{s}\right]$} & adsorbed water vapour mass per unit time \\
$O$ & {$\left[\mathrm{~m}^{2}\right]$} & surface area
\end{tabular}




\begin{tabular}{|c|c|c|}
\hline$t$ & [s] & time \\
\hline$V$ & {$\left[m^{3}\right]$} & total (store) volume \\
\hline$w_{H 2 O}$ & {$\left[\mathrm{~kg}_{\mathrm{H} 2 \mathrm{O}} / \mathrm{kg}\right]$} & water mass fraction: mass $\mathrm{H}_{2} \mathrm{O}$ per total mass \\
\hline$x$ & {$\left[k g_{H 2 O} / k g_{s, 0}\right]$} & water load: mass $\mathrm{H}_{2} \mathrm{O}$ per dry solid mass \\
\hline$z$ & {$[m]$} & axial coordinate \\
\hline$\alpha$ & {$\left[W /\left(m^{2} K\right)\right]$} & heat transfer coefficient \\
\hline$\beta_{\mathrm{H} 2 \mathrm{O}}$ & {$[m / s]$} & mass transfer coefficient \\
\hline$\varepsilon$ & {$[-]$} & void fraction \\
\hline$\vartheta$ & {$\left[{ }^{\circ} \mathrm{C}\right]$} & temperature \\
\hline$\lambda$ & {$[W /(m K)]$} & (effective) thermal conductivity \\
\hline$\rho$ & {$\left[\mathrm{kg} / \mathrm{m}^{3}\right]$} & density \\
\hline \multicolumn{3}{|c|}{ Subscripts } \\
\hline$g$ & & gaseous phase (moist air) \\
\hline$s$ & & solid phase (zeolite) \\
\hline$s, 0$ & & dry solid phase \\
\hline
\end{tabular}

CWS: A quasi-homogeneous 2D-model accounting for temperature and mass variation in the axial and radial space coordinate is used. The model equation for heat and mass transport in a cylindrical packed bed with reaction can be written as follows:

Heat balance:

$$
\begin{array}{r}
{\left[\psi \rho_{f} c_{p, f}+(1-\psi) \rho_{s} c_{p, s}\right] \frac{\partial T}{\partial t}=\lambda_{\alpha x} \frac{\partial^{2} T}{\partial z^{2}}+\lambda_{r}\left[\frac{\partial^{2} T}{\partial r^{2}}+\frac{1}{r} \frac{\partial T}{\partial r}\right]} \\
-u_{0} \rho_{f} c_{p, f} \frac{\partial T}{\partial z}+(1-\psi) \rho_{s, 0} R\left(-\Delta H_{R}\right)
\end{array}
$$

Mass balance (water vapour):

$$
\begin{aligned}
& \psi \frac{\partial \rho_{v^{*}}}{\partial t}=-u \psi \frac{\partial \rho_{v^{*}}}{\partial z}+D_{a x}^{+} \frac{\partial^{2} \rho_{v^{*}}}{\partial z^{2}}+D_{r}^{+}\left[\frac{\partial^{2} \rho_{v^{*}}}{\partial r^{2}}+\frac{1}{r} \frac{\partial \rho_{v^{*}}}{\partial r}\right] \\
& -R(1-\psi) \rho_{s, 0}
\end{aligned}
$$

Mass balance (solid):

$$
\frac{\partial \rho_{s}}{\partial t}=R \rho_{s, 0}
$$

The source term $R$ in the equations (8) to (10) describes the reaction kinetic of solid with water vapour and includes both adsorption and hydration processes (or desorption and dehydration respectively). The precise description of the source term will be one main focus of research as it determines the overall reaction rate and thus the thermal output of the reactor.

For the determination of the heat and mass transfer coefficient in a packed bed several empirical correlations are available in literature. Based on experimental investigations parameter identification will be used to determine the characteristic correlation parameters.

The boundary conditions of the model are given by: 


$$
\begin{aligned}
r=R \rightarrow & \Lambda_{r} \frac{\partial T}{\partial r}=\alpha_{w}\left(T_{w}-T\right) \\
& \frac{\partial \rho}{\partial r}=0 \\
z=0 \rightarrow & u_{0} \rho_{f} c_{f}\left(T_{\text {cin }}-T\right)=-\Lambda_{a x} \frac{\partial T}{\partial z} \\
& u_{0}\left(\rho_{v^{*}, \text { in }}-\rho_{v^{*}}\right)=-D_{a x} \frac{\partial \rho_{v^{*}}}{\partial z} \\
z=L \rightarrow & \frac{\partial T}{\partial z}=\frac{\partial \rho_{v^{*}}}{\partial z}=0
\end{aligned}
$$

The fluid flow in the porous media is described by the Brinkmann equation which incorporates the Darcy law into the Stoke's equation. The equations of motions are given by:

\section{Continuity equation:}

$$
\nabla \cdot \mathbf{u}=0
$$

Momentum equation:

$$
-\nabla p+\eta \nabla^{2} \mathbf{u}-\frac{\eta}{k} \mathbf{u}=0
$$

\begin{tabular}{|c|c|c|}
\hline$c_{p}$ & {$[\mathrm{~J} /(\mathrm{kgK})]$} & specific heat capacity \\
\hline$D+$ & {$\left[\mathrm{m}^{2} / \mathrm{s}\right]$} & effective mass dispersion coefficient \\
\hline$d_{p}$ & {$[m]$} & particle diameter \\
\hline$\Delta H_{R}$ & {$\left[\mathrm{~J} / \mathrm{kg} g_{v}\right]$} & reaction enthalpy \\
\hline k & {$\left[m^{2}\right]$} & permeability of the fixed bed \\
\hline$p$ & {$[\mathrm{~Pa}]$} & pressure \\
\hline$r$ & {$[m]$} & radial coordinate \\
\hline$R$ & {$\left[k g_{v} /\left(k g_{s, 0} s\right)\right]$} & overall reaction rate \\
\hline$T$ & {$[K]$} & temperature \\
\hline$u$ & {$[m / s]$} & actual velocity / velocity vector \\
\hline$u_{0}$ & {$[m / s]$} & superficial velocity \\
\hline$z$ & {$[m]$} & axial coordinate \\
\hline$\eta$ & {$[\mathrm{kg} /(\mathrm{m} \mathrm{s})]$} & effective viscosity \\
\hline$\lambda$ & {$[W /(m K)]$} & thermal conductivity \\
\hline$\rho_{f}$ & {$\left[k g_{f} / m_{f}^{3}\right]$} & fluid density \\
\hline$\rho_{s, 0}$ & {$\left[\mathrm{~kg}_{s, 0} / \mathrm{m}_{\mathrm{s}}^{3}\right]$} & density of the dry solid \\
\hline$\rho_{s}$ & {$\left[k g_{s} / m_{s}^{3}\right]$} & density of the solid \\
\hline$\rho_{v^{*}}$ & {$\left[k g_{v} / m_{f}^{3}\right]$} & absolute humidity \\
\hline$\psi$ & {$\left[m_{f}^{3} / m_{R}^{3}\right]$} & fixed bed porosity \\
\hline
\end{tabular}

The permeability $k$ depends on the particle diameter $d_{p}$ and the bed porosity $\psi$.

$$
k=\frac{1}{A} \frac{\psi^{3}}{(1-\psi)^{2}} d_{p}^{2}
$$

Nomenclature CWS:

\section{COMPUTATIONAL PROCEDURE}


MONOSORP: The set of highly nonlinear partial differential and algebraic equations is solved by the method of lines solver PDEXPACK developed at University of Stuttgart with the Conrad-Zuse Zentrum, Berlin /1,2/. Second order finite differences are applied for axial discretization. Both the grid density and the time step size are fully adaptive ensuring the requested accuracy at reasonable computing time. PDEX is originally running as standalone program on UNIX systems; however, the Fortran code has recently been transferred and implemented in a TRNSYS16 Type.

CWS: The 2D-model will be implemented and solved by the software package COMSOL/ Multiphysics using FEM. For long term system simulations with TRNSYS, calculations based on an adapted 1D Monosorp model might be carried out.

\section{RESULTS \& DISCUSSION}

In the current state, results are only available for the Monosorp model. The current implementation of this model is based on the following main assumptions:

- It is assumed that the adsorption behaviour of the honey comb zeolite can be described by one representative channel. It has been reported that $1 \mathrm{D}$ modelling does not significantly lack valuable adsorption relevant information compared to the three-dimensional model.

- The mass flow is assumed to be laminar within the channel and evenly distributed over the channel cross section.

- The diffusion of the $\mathrm{H}_{2} \mathrm{O}$-molecules into the zeolite layer is taken into account by a simple linear driving force assumption with lumped parameters.

- The adsorption enthalpy $\Delta \mathrm{h}_{\mathrm{ads}}$ is constant and not depending on the water load of the zeolite.

The following table shows the main parameter values identified and used for the numerical simulation of the Monosorp prototype unit:

\begin{tabular}{|l|c|}
\hline mean adsorption enthalpy & $3600 \mathrm{~kJ} / \mathrm{kg}$ \\
\hline maximum water upload of zeolite & $18 \%$ \\
\hline density of zeolite & $891 \mathrm{~kg} / \mathrm{m}^{3}$ \\
\hline specific heat capacity of zeolite & $1,07 \mathrm{~kJ} /(\mathrm{kg} \mathrm{K})$ \\
\hline void fraction of honey comb & $17,4 \%$ \\
\hline
\end{tabular}

In Figure 1 simulation results of a desorption process are plotted: starting with a partly loaded store, a desorption front is slowly moving from the inlet to the middle. However, reaching the back end of the store, humidity taken up by the air flow while passing the water-loaded front part is re-adsorbed. In turn, a dry air flow at high temperatures is leaving the store until the water load is completely shifted towards the back end - not until then the real regeneration of the store will begin.

The numerical approach developed within the Monosorp project seems practical whenever sorption processes are to be modelled in one dimension. In combination with the PDEX solver this is a computationally very efficient way of getting more detailed information about the dynamic interconnections between mass and heat transfer - with the option to use the same model in dynamic long term system simulations. 


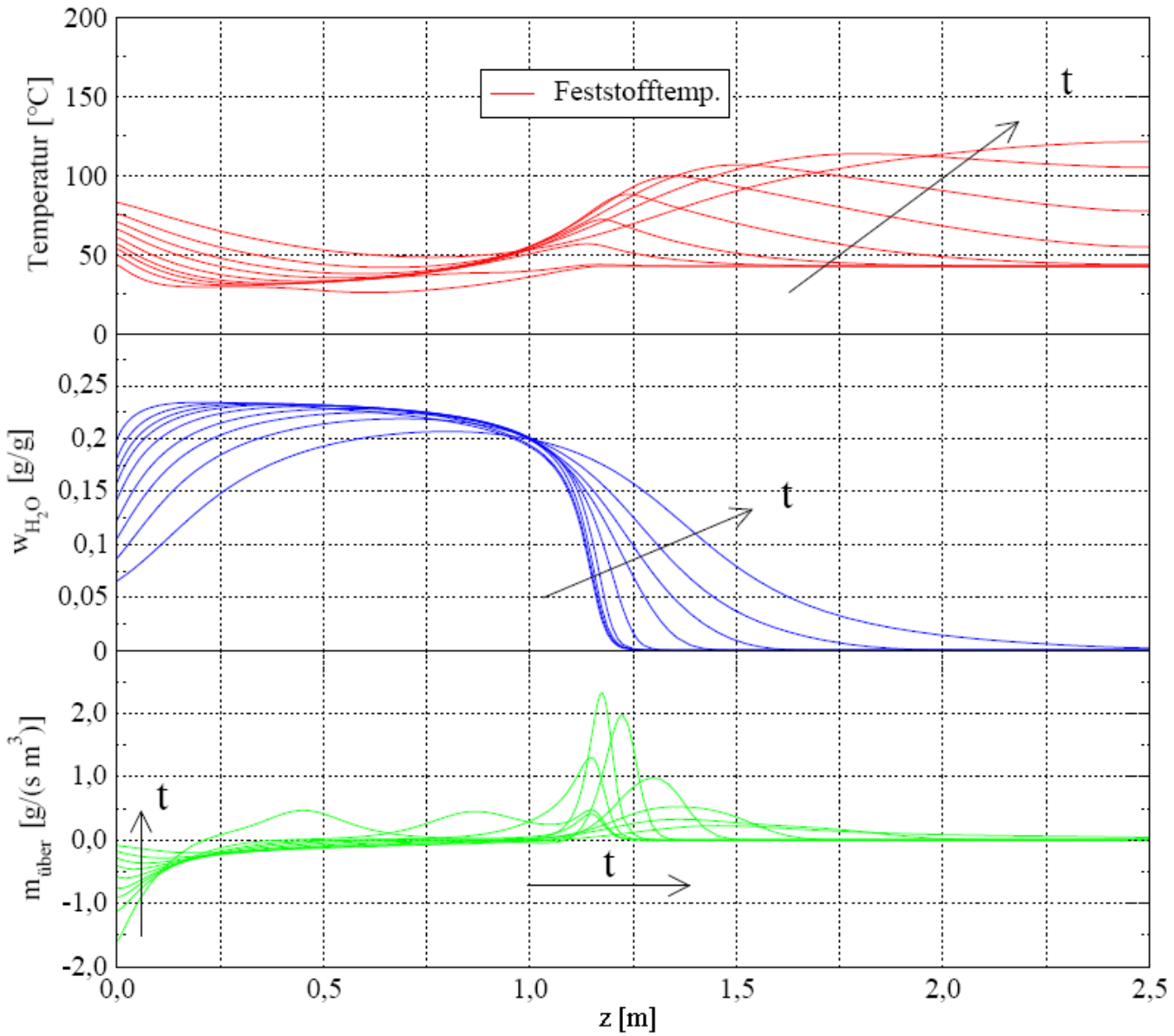

Figure 1: Simulation of local solid temperature, water load and transferred vapour mass flow during an exemplary $5 h$-desorption process of a partly loaded adsorption store.

\section{REFERENCES}

[1] U. Nowak, J. Frauhammer and U. Nieken, A fully adaptive algorithm for parabolic partial differential equations in one space dimension. Comput. Chem. Eng. 20 (1996), pp. 547-561.

[2] J. Frauhammer, Numerische Loesung von eindimensionalen parabolischen Systemen mit adaptiven Gittern, Master Thesis, ICVT, University Stuttgart, 1992.

[3] $\mathrm{H}$. Kerskes, $\mathrm{NO}_{\mathrm{x}}$-Speicher-Katalysatoren und ihr Einsatz in Diesel-Fahrzeugen, Phd, 2001.

[4] Th. Kirchner, Experimentelle Untersuchungen und Simulation der Autoabgaskatalyse zur Verbesserung des Kaltstartverhaltens, Phd, 1997.

[5] N. Nestle, R. Kimmich, Über die Bedeutung von Diffusionsgrenzschichten bei Ionenaustauschvorgängen. Heat and Mass Transfer, 32, 9-15, 1996. 


\section{Closure}

It might be clear from the presented results in this report that numerous methods are available to model the physical processes in compact heat storage materials on various scales. However, it is also clear that there are quite a few white spots in both PCM- and TCM-research. Whereas the PCM-research seems to focus more on the larger scales, trying to develop models which can be used at the reactor-scale, the TCM-research so far seems to concentrate more on fundamental issues. The authors are aware that this conclusion might be premature because it is based on a small selection of all the work done worldwide in this area of research.

The importance of computer simulations of the materials applied in thermal energy storage systems is rapidly growing. This calls for validated numerical techniques on various scales which can be used on the one hand to design new reactor concepts and on the other hand to develop new energy storage materials and/or composites. Hopefully the forthcoming report on (validated) numerical models (deliverable A3.5) shows a broader coverage of all scales (micro-, meso-, macro-, multi- and reactor-scale) compared to the coverage in the present report.

The present work is performed under the umbrella of the IEA Solar Heating and Cooling programme Task 42 (ECES annex 24). Input to this report by the authors was provided on a voluntary basis and is highly appreciated by the editors. In addition thanks go to all working group members who contributed to the fruitful discussions during the expert meetings. 


\section{Short Description of Task 42 / annex 24}

From past IEA SHC and ECES tasks it was concluded that a broad and basic research and development initiative is needed to find and improve compact thermal energy storage materials. The IEA joint Task/Annex 42/24 brings together experts from both the materials development field and the systems integration fields. In four years, the task aims at having finished the first steps towards a new generation of thermal storage technologies.

\section{OBJECTIVE}

The overall objective of this task is to develop advanced materials and systems for the compact storage of thermal energy. This can be subdivided into seven specific objectives:

- to identify, design and develop new materials and composites for compact thermal energy storage,

- to develop measuring and testing procedures to characterise new storage materials reliably and reproducibly,

- to improve the performance, stability, and cost-effectiveness of new storage materials,

- to develop multi-scale numerical models, describing and predicting the performance of new materials in thermal storage systems,

- to develop and demonstrate novel compact thermal energy storage systems employing the advanced materials,

- to assess the impact of new materials on the performance of thermal energy storage in the different applications considered, and

- to disseminate the knowledge and experience acquired in this task.

A secondary objective of this task is to create an active and effective research network in which researchers and industry working in the field of thermal energy storage can collaborate.

\section{SCOPE}

This task deals with advanced materials for latent and chemical thermal energy storage, and excludes materials related to sensible heat storage. The task deals with these materials on three different scales:

- material scale, focused on the behaviour of materials from the molecular to the 'few particles' scale, including e.g. material synthesis, micro-scale mass transport, and sorption reactions;

- bulk scale, focused on bulk behaviour of materials and the performance of the storage in itself, including e.g. heat, mass, and vapour transport, wall-wall and wall-material interactions, and reactor design;

- system scale, focused on the performance of a storage within a heating or cooling system, including e.g. economical feasibility studies, case studies, and system tests.

Because seasonal storage of solar heat for solar assisted heating of buildings is the main focus of the SHC IA, this will be one of the primary topics of this task. However, because there are many more relevant applications for TES, and because materials research is not and can not be limited to one application only, this task will focus on multiple application areas.

In the Task kick-off meeting it was decided to subdivide the Applications Subtask into three Working Groups, corresponding to three different temperature levels of thermal energy storage, as depicted below. 


\section{STRUCTURE}

To achieve the maximum amount of cross-fertilisation between the different backgrounds of the two Implementing Agreements and experts in this Joint Task, the Task is organised in a matrix-like structure (see diagram below).

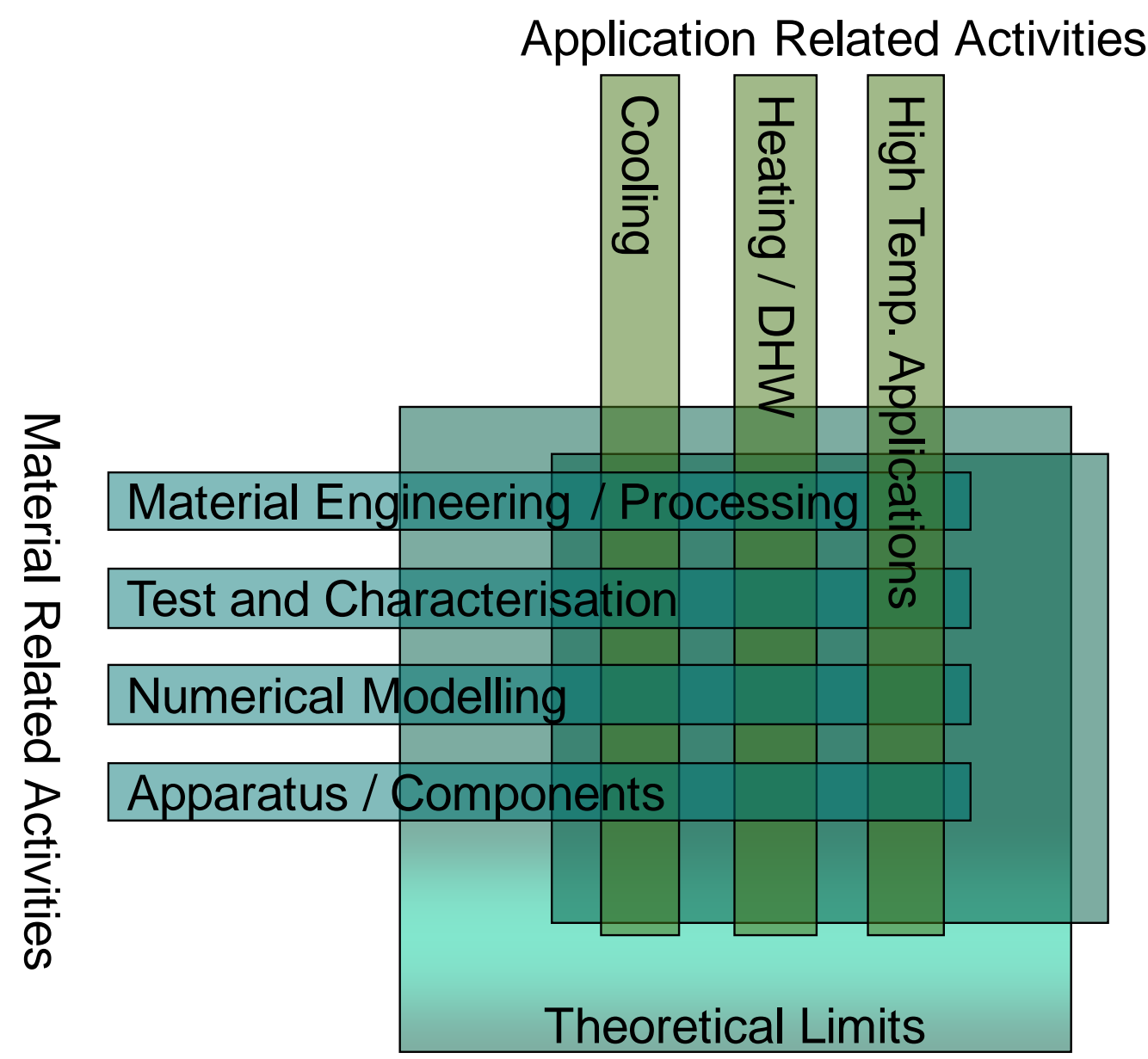




\section{Short description Working Group A3 Numerical Modelling}

\section{INTRODUCTION}

The activities in this working group are aimed at developing and testing numerical models that help to understand and optimise the material behaviour and the dynamic behaviour of compact thermal energy storage systems and components based on Phase Change Materials (PCM's) and Thermo Chemical Materials (TCM's). Ultimately, these numerical models could help to find ways to optimise the materials in combination with the system components. The activities in this working group help to lay the foundation for such models.

The Working Group includes the following activities:

- Micro-scale modelling

- Meso-scale modelling

- Macro-scale modelling

- Multi-scale approach

- Thermo-mechanical modelling

- Reactor models

Not all activities receive the same amount of attention in the Working Group and the distinction between the various scales is not always clear. The figure below presents an attempt to quantify the micro-, meso- and macro-scales in a time-length framework but it has to be realised that the definition of the scales is highly dependent on the problem at hand.

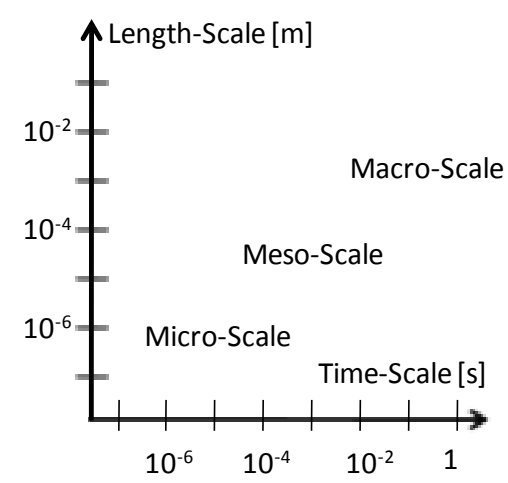

Figure 1: Definition of micro-, meso- and macro-scales in a time-length framework.

\section{DELIVERABLES}

The following deliverables are set during the first kick-off meeting in Bad Tölz, February $11-13,2009$.

\begin{tabular}{lll}
\hline \# & Deliverable & Month \\
\hline A3.1 & $\begin{array}{l}\text { Report on modeling techniques of TCM/PCM-materials on micro-, } \\
\text { meso- and macro scales as used by the participants in WGA3 }\end{array}$ & 12 \\
A3.2 & $\begin{array}{l}\text { Collection of experimental data on the behavior of TCM/PCM- } \\
\text { materials which can be used to bench-mark numerical codes }\end{array}$ & 18 \\
A3.3 & $\begin{array}{l}\text { Progress report on the (validated) numerical models developed } \\
\text { for the micro-, meso-, macro and multi-scale }\end{array}$ & 30 \\
A3.4 & $\begin{array}{l}\text { Overview of material properties required for increased storage } \\
\text { performance compared to conventional storage techniques } \\
\text { Final report on the (validated) numerical models developed for } \\
\text { the micro-, meso-, macro and multi-scale }\end{array}$ & 48 \\
\hline
\end{tabular}




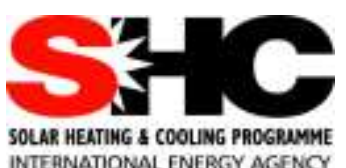

\section{IEA Solar Heating and Cooling Programme}

The International Energy Agency (IEA) is an autonomous body within the framework of the Organization for Economic Co-operation and Development (OECD) based in Paris. Established in 1974 after the first "oil shock," the IEA is committed to carrying out a comprehensive program of energy cooperation among its members and the Commission of the European Communities.

The IEA provides a legal framework, through IEA Implementing Agreements such as the Solar Heating and Cooling Agreement, for international collaboration in energy technology research and development (R\&D) and deployment. This IEA experience has proved that such collaboration contributes significantly to faster technological progress, while reducing costs; to eliminating technological risks and duplication of efforts; and to creating numerous other benefits, such as swifter expansion of the knowledge base and easier harmonization of standards.

The Solar Heating and Cooling Programme was one of the first IEA Implementing Agreements to be established. Since 1977, its members have been collaborating to advance active solar and passive solar and their application in buildings and other areas, such as agriculture and industry. Current members are:

$\begin{array}{lll}\text { Australia } & \text { Finland } & \text { Portugal } \\ \text { Austria } & \text { France } & \text { South Africa } \\ \text { Belgium } & \text { Italy } & \text { Spain } \\ \text { Canada } & \text { Mexico } & \text { Sweden } \\ \text { Denmark } & \text { Netherlands } & \text { Switzerland } \\ \text { European Commission } & \text { New Zealand } & \text { United States } \\ \text { Germany } & \text { Norway } & \end{array}$

A total of 44 Tasks have been initiated, 33 of which have been completed. Each Task is managed by an Operating Agent from one of the participating countries. Overall control of the program rests with an Executive Committee comprised of one representative from each contracting party to the Implementing Agreement. In addition to the Task work, a number of special activitiesMemorandum of Understanding with solar thermal trade organizations, statistics collection and analysis, conferences and workshops - have been undertaken.

To find Solar Heating and Cooling Programme publications and learn more about the Programme visit www.iea-shc.org or contact the SHC Secretariat, Pamela Murphy, e-mail: pmurphy@kmgrp.net. 
Current Tasks \& Working Group:

Task $36 \quad$ Solar Resource Knowledge Management

Task $37 \quad$ Advanced Housing Renovation with Solar \& Conservation

Task $38 \quad$ Solar Thermal Cooling and Air Conditioning

Task 39 Polymeric Materials for Solar Thermal Applications

Task $40 \quad$ Towards Net Zero Energy Solar Buildings

Task $41 \quad$ Solar Energy and Architecture

Task $42 \quad$ Compact Thermal Energy Storage

Task $43 \quad$ Rating and Certification Procedures

Task $44 \quad$ Solar and Heat Pump Systems

Completed Tasks:

Task 1 Investigation of the Performance of Solar Heating and Cooling Systems

Task 2 Coordination of Solar Heating and Cooling R\&D

Task $3 \quad$ Performance Testing of Solar Collectors

Task 4 Development of an Insolation Handbook and Instrument Package

Task 5 Use of Existing Meteorological Information for Solar Energy Application

Task $6 \quad$ Performance of Solar Systems Using Evacuated Collectors

Task $7 \quad$ Central Solar Heating Plants with Seasonal Storage

Task $8 \quad$ Passive and Hybrid Solar Low Energy Buildings

Task $9 \quad$ Solar Radiation and Pyranometry Studies

Task $10 \quad$ Solar Materials $R \& D$

Task $11 \quad$ Passive and Hybrid Solar Commercial Buildings

Task $12 \quad$ Building Energy Analysis and Design Tools for Solar Applications

Task $13 \quad$ Advanced Solar Low Energy Buildings

Task $14 \quad$ Advanced Active Solar Energy Systems

Task $16 \quad$ Photovoltaics in Buildings

Task $17 \quad$ Measuring and Modeling Spectral Radiation

Task 18 Advanced Glazing and Associated Materials for Solar and Building Applications

Task 19 Solar Air Systems

Task $20 \quad$ Solar Energy in Building Renovation

Task $21 \quad$ Daylight in Buildings

Task $22 \quad$ Building Energy Analysis Tools

Task $23 \quad$ Optimization of Solar Energy Use in Large Buildings

Task $24 \quad$ Solar Procurement

Task $25 \quad$ Solar Assisted Air Conditioning of Buildings

Task $26 \quad$ Solar Combisystems

Task $27 \quad$ Performance of Solar Facade Components

Task $28 \quad$ Solar Sustainable Housing

Task $29 \quad$ Solar Crop Drying

Task $31 \quad$ Daylighting Buildings in the $21^{\text {st }}$ Century

Task $32 \quad$ Advanced Storage Concepts for Solar and Low Energy Buildings

Task $33 \quad$ Solar Heat for Industrial Processes

Task $34 \quad$ Testing and Validation of Building Energy Simulation Tools

Task $35 \quad$ PV/Thermal Solar Systems

Completed Working Groups:

CSHPSS, ISOLDE, Materials in Solar Thermal Collectors, Evaluation of Task 13 Houses, and Daylight Research 